\title{
S Research Square
Durability Performance On Alkali Activated \\ Metakaolin And Bottom Ash Based Geopolymer \\ Concrete
}

Logesh Kumar M ( $\sim$ logeshcivil@gmail.com)

Sona College of Technology https://orcid.org/0000-0002-5382-4316

Dr. Revathi V

KSR College of Engineering

\section{Research Article}

Keywords: Metakaolin, Bottom ash, ambient curing, durability, sorptivity, water absorption.

Posted Date: July 14th, 2021

DOI: https://doi.org/10.21203/rs.3.rs-703480/v1

License: (c) (i) This work is licensed under a Creative Commons Attribution 4.0 International License.

Read Full License 


\section{Abstract}

This paper presents an experimental investigation on the durability properties of metakaolin (MK) and bottom ash (BA) blended geopolymer under different environmental exposure. The blended geopolymer concrete (GPC) was prepared with sodium based alkaline activators under ambient curing temperature. The concentration of sodium hydroxide used was $8 \mathrm{M}$. The ratio of sodium silicate to sodium hydroxide was kept as 2.0. The performance of blended geopolymer concrete was compared with conventional concrete (CC). The test results reveal that blended geopolymer concrete develops a better performance against sulphate and acid resistance. Also, MK-BA GPC shows enhanced performance over the conventional concrete in terms of sorptivity, rapid chloride and water absorption.

\section{Introduction}

Ordinary Portland cement is the most popular binder material for producing concrete. The usage of cement is ever increasing due to its ability to gain early strength as well as prolonged strength gain. However, it is energy intensive and also consumes large amount of natural materials for its production. Further, production of every one ton of cement releases about 1 ton of $\mathrm{CO}_{2}$ in to atmosphere promoting global warming and deterioration of ecosystem [1-3]. It is being noted from the last decade, extensive research works have been carried out in the field of advance growth in inorganic geopolymers because of its extensive scope of prospective applications of these supplementary materials. Different studies are being found in the literature on the performance, synthesis, behaviour and function of geopolymer materials [4-5].

Geopolymer is an inorganic alumino-silicate compound synthesized from geological material or industrial by-products such as fly ash, slag, rice husk ash etc. Further, geopolymers are inorganic in nature and it can be synthesized by means of external activators under alkaline medium and also the proper selection of source materials which are rich in Si and Al content. The chemical mechanism between Si-Al minerals and alkaline liquids consist of destruction of $\mathrm{Si}$ and $\mathrm{Al}$ atoms from source materials followed by coagulation and condensation of precursor into monomers and finally monomers into polymeric crystalline structures [6-8]. Eventually the polymerization process develops fast accelerated chemical reaction under alkaline environment on Si:Al minerals that forms three dimensional polymeric chain and ring structure consisting $\mathrm{Si}-\mathrm{Al}$ - O bonds [9].

In general, when the bottom ash was grined finer it will be of more reactive and thereby directly imparts on the high compressive strength in geopolymer specimens [10-11]. The effect of curing mode on the properties of geopolymer mortar made using combustion coal bottom ash shows that dry curing decreases in compressive strength than ambient curing. Also, dry curing exhibits porous microstructure where as ambient cured specimen exhibit homogenous and compact matrix [12]. The geopolymeric reaction depends on the fineness and pore size of material used. It has been observed that fine bottom ash improves the performance of geopolymer in terms of sulphate resistance as well as sorptivity [13]. Subsequently, the effect of molar ratio of $\mathrm{Si}$ to $\mathrm{NaOH}$ and $\mathrm{Na} 2 \mathrm{SiO} 3$ to $\mathrm{NaOH}$ on compressive strength of 
geopolymer mortar. It is noted that mortar with low $\mathrm{Si}$ to $\mathrm{NaOH}$ attained maximum compressive strength. Further, proper selection of molar ratio can cause high geopolymer reaction at ambient temperature [14]. Further, the durability performance of lignite bottom ash were studied and the test results indicates that finer bottom ash imparts high compressive strength and also exhibit better performance in terms of durability than cement mortar [10 \& 15].

Metakaolin which is generally used as pozzolanic micro filler material in terms of high strength and as well as high performance concrete. The characteristics of metakaolin based geopolymer in terms of strength parameters as well as durable properties shows tremendous performance when compare with OPC [16]. Also, when compared with individual score materials performance, blended nature exhibits better results [17-18]. The calcination temperature and period of calcination plays an important role in developing the strength of the matrix [19]. Consequently, the kinetics of geopolymeric reaction of metakaolin and activators shows that silica and alumina content will have direct impact on early strength. Also, increase in molar ratio of Si/Al imparts strength gain at later ages [20]. The increase in fineness of metakaolin enhances the strength of binder material [21]. Also, metakaolin synthesized with sodium hydroxide and sodium silicate imparted the dense texture and high resistant to surface scratching to geopolymer [22].

The performance of geopolymer materials depends on the various factors such as choice of selection of source materials, fineness of the materials used, and mode of curing $[19,23]$. Mode of curing has been one of the major issue factors for geopolymer technology. But by taking into account of proper selection of source materials as well as the suitable activators consideration one can able to cast the geopolymer concrete in cast - in - situ under ambient temperature itself $[22,24,25]$. Further, it has been noted that proper selection of molar ratio can cause greater geopolymeric reaction at ambient temperature [14].

In the present experimental investigation, durability properties such as sulphate attack, acid attack and their weight loss and its strength retention were tested at different period of time. Also, sorptivity, rapid chloride penetration test and water absorption tests were also carried out to explore the performance of metakaolin - bottom ash geopolymer concrete activated by sodium based alkaline activators under ambient temperature.

A profuse research work was done earlier in the field of geopolymer concrete by using different aluminasilicate based materials as source materials. Moreover, the performance of geopolymer concrete when they are blended with two or more source materials together under different curing conditions are being investigated by different researchers. But, the synthesis effect on metakaolin and bottom ash geopolymer source materials were not been explored so far. In this background, a venture has been taken up to study the durability performance of MK- BA geopolymer concrete when it is exposed to different period of time under various environment circumstances.

\section{Materials}




\subsection{Cement}

Ordinary Portland cement (OPC) of 53 grade, satisfying the requirements of BIS 12269-2013 [26] has been used to produce control mix. The physical properties of the cement were measured as per BIS 4031 - 1988 \& $1999[27,28]$ and the results are summarized in Table 1. Also, the chemical properties of cement were analysed using the procedure prescribed by BIS: 4032 - 1985 [29] and the result are presented in Table 2.

Table 1

Physical and Mechanical Properties of Cement

\begin{tabular}{|c|c|c|c|c|}
\hline S.No & \multicolumn{2}{|l|}{ Characteristics } & Result & Specifications as per BIS $12269-2013$ \\
\hline 1. & \multicolumn{2}{|l|}{ Specific Gravity } & 3.14 & 3.15 \\
\hline 2. & \multicolumn{2}{|l|}{$\begin{array}{l}\text { Fineness by Blaine's Air } \\
\text { Permeability }\end{array}$} & $305 \mathrm{~m}^{2} / \mathrm{kg}$ & Not less than $225 \mathrm{~m}^{2} / \mathrm{kg}$ \\
\hline 3. & \multicolumn{2}{|l|}{ Normal Consistency } & $30 \%$ & - \\
\hline 4. & \multicolumn{2}{|l|}{ Initial Setting Time } & $48 \mathrm{~min}$ & Not less than $30 \mathrm{~min}$ \\
\hline 5. & \multicolumn{2}{|l|}{ Final Setting Time } & $246 \min$ & Not more than 600 min \\
\hline 6. & \multicolumn{2}{|c|}{ Soundness Le-Chatelier Method } & $1.2 \mathrm{~mm}$ & Not more than $10 \mathrm{~mm}$ \\
\hline \multirow[t]{3}{*}{7.} & \multirow[t]{3}{*}{ Compressive Strength } & 3 days & $28.6 \mathrm{MPa}$ & Not less than $27 \mathrm{MPa}$ \\
\hline & & 7 days & $37.3 \mathrm{MPa}$ & Not less than $37 \mathrm{MPa}$ \\
\hline & & 28 days & $55.4 \mathrm{MPa}$ & Not less than $53 \mathrm{MPa}$ \\
\hline
\end{tabular}

Table 2

Chemical Properties of Cement

\begin{tabular}{|lll|}
\hline S.No & Chemical component & Percentage \\
\hline 1. & $\mathrm{CaO}$ & 63.5 \\
\hline 2. & $\mathrm{SiO}_{2}$ & 22.7 \\
\hline 3. & $\mathrm{Al}_{2} \mathrm{O}_{3}$ & 5.45 \\
\hline 4. & $\mathrm{Fe}_{2} \mathrm{O}_{3}$ & 4.34 \\
\hline 5. & $\mathrm{MgO}$ & 1.52 \\
\hline 6. & $\mathrm{Cl}$ & 0.02 \\
\hline 7. & $\mathrm{LOI}$ & 1.4 \\
\hline
\end{tabular}


Metakaolin (MK) is the product which is obtained by the calcinations of kaolin under $650^{\circ} \mathrm{Cto} 750^{\circ} \mathrm{C}$. Metakaolin used in this study was procured from Jeetmul industries, Chennai. The metakaolin having average particle size 5 microns and specific surface area of $20000 \mathrm{~m}^{2} / \mathrm{gm}$. The specific gravity of metakaolin is 2.5. The chemical composition and mineral compositions are determined by X-ray fluorescence (XRF) as shown in Fig. 1 and Table 3. The microstructure of the metakaolin material were carried out by Scanning Electron Microscope (SEM) analysis and from the image it has been inferred that particles are irregular in shape, glassy structure and as well as some impurities are also found and it has been shown in the Fig. 2

Table 3

Compounds of mineral percentage in metakaolin and bottom ash

\begin{tabular}{|lll|}
\hline Mineral Compounds & Metakaolin (\%) & Bottom Ash (\%) \\
\hline $\mathrm{KAISi}_{3} \mathrm{O}_{8}$ (Orthoclase) & 5.02 & 2.78 \\
\hline $\mathrm{CaAl}_{2} \mathrm{Si}_{2} \mathrm{O}_{8}$ (Anorthite) & 12.40 & 2.68 \\
\hline $\mathrm{Al}_{2} \mathrm{O}_{3}$ (Corundum) & 20.85 & 30.87 \\
\hline $\mathrm{Fe}_{2} \mathrm{O}_{3}$ (Hematite) & 4.48 & 2.90 \\
\hline $\mathrm{SiO}_{2}$ (Quartz) & 55.25 & 57.97 \\
\hline $\mathrm{TiO}_{2}$ (Rutile) & 1.96 & 2.44 \\
\hline
\end{tabular}

\subsection{Bottom Ash}

In this study, bottom ash which was collected from the Mettur Thermal power plant station. Bottom ash is in a moist state condition, it was dried well and grained as much as possible to attain low particle size. The specific surface area of bottom ash is $3460 \mathrm{~cm} 2 / \mathrm{gm}$ and the specific gravity was found to be 2.17 . The chemical composition and mineral compositions are determined by $\mathrm{X}$-ray fluorescence (XRF) as shown in Fig. 3 and Table 3. Also, SEM images reveal that the particles are almost spherical in shape with some minor broken cenosphere revealing the existence of silica and alumina in high proportions and it has shown in Fig. 4.

\subsection{Alkali Activator}

The chemical solution which is responsible for the process of polymerization is known as alkaline activator solutions. Sodium based alkaline activators such as sodium hydroxide and sodium silicate were used in this work. The sodium silicate and sodium hydroxide are purchased from the local supplier. The ratio of silica modulus in sodium silicate solution is 2.14 . The sodium hydroxide flakes having purity of about $97 \%-98 \%$ were dissolved in water to make a solution for the required molarity. Further, the chemical composition of sodium silicate solution is having $29 \%$ of $\mathrm{SiO}_{2}, 13.7 \%$ of $\mathrm{Na}_{2} \mathrm{O}$ and water of 
$55.9 \%$ by weight. Also, the alkaline activator solution was prepared a day before the time of casting which is a key responsible for inducing the polymerization process.

\subsection{Aggregates}

The fine aggregate used in this study was locally available river sand confirming to zone III. The specific gravity of fine aggregate is as 2.63 . Also, locally available coarse aggregate having specific gravity of about 2.26 was used. The characteristics of fine and coarse aggregates are in conformity with the requirements prescribed BIS 383-1970 [30]. Further, the physical properties of coarse and fine aggregates are tested as BIS 2386-1963 [31] and the test results are presented in Table 4.

Table 4

Physical Properties of Aggregates

\begin{tabular}{|lll|}
\hline Tests & Fine Aggregate & Coarse Aggregate \\
\hline Specific Gravity & 2.63 & 2.69 \\
\hline Bulk density & $1732 \mathrm{~kg} / \mathrm{m}^{3}$ & $1697 \mathrm{~kg} / \mathrm{m}^{3}$ \\
\hline Fineness Modulus & 2.26 & 6.71 \\
\hline Water absorption & $1.45 \%$ & $0.5 \%$ \\
\hline Grading Zone & III & - \\
\hline Crushing Value & - & $18.5 \%$ \\
\hline Impact Value & - & $19.6 \%$ \\
\hline
\end{tabular}

\section{Experimental Program}

Based on the earlier studies made by the authors [32] on geopolymer mortar of metakaolin and bottom ash was varied with liquid to binder ratio from 0.48 to 0.52 with $8 \mathrm{M}$ for different mix proportions under ambient curing. It has been found that the source material such as metakaolin and bottom ash of equal proportions with liquid to binder ratio of 0.5 identified as promising mix to make geopolymer concrete. For casting the geopolymer concrete, the density was taken as $2400 \mathrm{~kg} / \mathrm{m} 3$ similar to conventional concrete. For geopolymer concrete casting, the mix design was carried out as per the guidelines prescribed [33,34]. To compare the test results, the conventional concrete was casted as per the guidelines [35]. From the test results, it has been observed that geopolymer concrete exhibits $49 \%$ of higher compressive strength than that of $\mathrm{CC}$. Also, the similar trend was exhibited in other mechanical properties also [36]. The same mix proportion will be adopted to cast and test the durability properties of geopolymer concrete specimens. The mix proportion of MK-BA GPC is presented in Table 5. In addition, control mix using cement as binder was designed as per prescribed [35] and the material quantity are also shown in Table 5. 
Table 5

Mix Proportions of CC and GPC

\begin{tabular}{|lll|}
\hline Materials $\left(\mathrm{Kg} / \mathrm{m}^{3}\right)$ & CC & MK - BA GPC \\
\hline Cement & 381 & - \\
\hline Metakaolin & - & 200 \\
\hline Bottom Ash & - & 200 \\
\hline Sodium Silicate & - & 133.38 \\
\hline Sodium Hydroxide & - & 66.7 \\
\hline Fine Aggregate & 833 & 540 \\
\hline Coarse Aggregate & 1084 & 1260 \\
\hline Water & 162 & - \\
\hline
\end{tabular}

\subsection{TEST PROCEDURE}

To study the behaviour of geopolymer samples under different environment such as sulphate, and acidic environment exposure. The geopolymer concrete samples were exposed to $5 \%$ of magnesium sulphate solution and $2 \%$ of sulphuric acid solution respectively. All the geopolymer concrete specimens are exposed to different environment only after 28 days of curing at ambient temperature. It is to be noted that, the duration of exposure on different solutions was 1, 3, 6 and 12 months and all the specimens were kept fully immersed in their corresponding solutions having total volume as four times the volume of specimens immersed. At the time of testing, the surface of specimen was wiped out and they are tested for weight and compressive strength at surface dry conditions. A total of 24 specimens were casted to determine the sulphate resistance of GPC and CC as prescribed [37], whereas 24 specimens were casted and tested to determine the acid resistance of GPC and CC in accordance with the guidelines [38].

To study the rate of sorptivity of the GPC and CC specimens, a cylindrical disc specimens having $100 \mathrm{~mm}$ diameter and $50 \mathrm{~mm}$ thickness were cast for determining the rate of sorptivity of GPC as well as CC. The sorptivity test was conducted in accordance with standard [39]. The test was carried out on 28 day cured specimens. The specimens were placed in a tray such that their bottom surface up to a height of $5 \mathrm{~mm}$ was in contact with water. This is to allow free movement of water through the bottom surface of specimen by capillarity. The sides of the specimens were covered with adhesive glue as show in Fig. 5 . The top surface which was not exposed to water was covered with plastic sheet. The mass of the specimen was recorded at the intervals as per mentioned in the code. The amount of water absorbed was calculated using the following equation.

$\mathrm{I}=\Delta \mathrm{m} / \mathrm{a} \times \mathrm{d}(1)$ 
Where I - absorption in $\mathrm{mm}$

$\Delta \mathrm{m}$ - the change in mass of the specimen in gm at the time $\mathrm{t}$

$\mathrm{a}$ - the exposed area of the specimen in $\mathrm{mm}^{2}$

$\mathrm{d}$ - Density of water in $\mathrm{gm} / \mathrm{mm}$

To evaluate the electrical conductance of concrete, a rapid indication of resistance to the dispersion of chloride ions has been determined by Rapid Chloride Penetration Test (RCPT) as per the guidelines prescribed [40]. A concrete disc having $50 \mathrm{~mm}$ thick and $100 \mathrm{~mm}$ diameter has been determined for the period of 6 hours. A potential difference of $60 \mathrm{~V}$ direct current was maintained across the specimen immersed in a $3 \%$ sodium chloride solution and the other in a $0.3 \mathrm{M}$ sodium hydroxide solution.

The passage of current was monitored at every 30 minutes till completion of

6 hours along with the temperature of the solution in each cell. The charge passed can be computed by using trapezoidal rules and it is expressed as coulombs [1 coulombs is 1 ampere seconds] and it has been calculated by the formula expressed in Eq. 3.3. A total of 18 specimens were cast to carry out rapid chloride penetration test on GPC and control concrete. The test was carried out on GPC and CC at the age of 28days, 56 days and 90 days of curing at room temperature and the specimens casted are shown in Fig. 6.

$Q=900 * 2 * I$ Cumulative coulombs Eq. (2)

$I_{\text {Cummulative }}=I_{0}+I_{30}+I_{60}+I_{90}+I_{120}+I_{150}+I_{180}+I_{210}+I_{240}+I_{270}+I_{300}+I_{330}+I_{360}$

where, $\mathrm{Q}=$ Charge passed (coulombs)

$\mathrm{I}_{0}=$ Current (amperes) immediately after voltage is applied

$\mathrm{I}_{\mathrm{t}}=$ Current (amperes) at't' minute after voltage is applied

The water absorption characteristics of MK-BA GPC and CC were determined at the age of 7 and 28 days using the procedure prescribed [41]. The test specimens of size $100 \times 100 \times 100 \mathrm{~mm}$ were used. The 7 and 28 days cured specimens of GPC and CC were dried in an oven at a temperature of about $100^{\circ} \mathrm{C}$ for 24 hours. Then the cured specimens were endorsed to cool at room temperature for 3 minutes. The initial mass of the specimens was noted as (A). Then the final mass of the specimens was recorded only after the immersion of specimens in water for 24 hours and it is noted as (B). Water absorption was calculated from Eq. 2.2 given below.

Water absorption \% = [(B-A)/A] x 100 Eq. (3)

\section{Results And Discussion}




\subsection{Resistance towards magnesium sulphate attack 4.1.1 Visual appearance}

The physical appearance of both geopolymer specimens and control concrete specimens exposed to magnesium sulphate solution over a period of 12 months shows that the shape and dimensions of the specimens are quiet intact and they are shown in Figs. 7 and 8. However, precipitation of white salt has been noticed on the surface of CC but GPC specimens are free from precipitate. The reason for precipitate over CC is due to magnesium takes part in the reaction replacing calcium in solid phases as a result of which brucite and magnesium silicates hydrates are formed. Existence of brucite on the control concrete surface lowers the $\mathrm{pH}$ of pore solution and then decomposes the calcium silicate hydrates as a result of which calcium is precipitated as gypsum in form of white precipitation [42]. As the GPC is free from calcium hydroxide and calcium silicate hydrates, the white precipitate has not been formed on its surface [43-45].

\subsubsection{Change in mass}

The results of the mass gain in control concrete and MK - BA GPC are shown in Table 6 and they are also depicted in the Fig. 9. It is obvious from the test results that mass of both concrete specimens are increased in mass marginally. However, when compared with the control concrete, GPC has demonstrated relatively less gain of mass. After 12 months of exposure GPC shows $2.08 \%$ of mass gain, where as CC explicit $3.95 \%$ of mass gain. Generally, the concrete having higher porosity, permeability and sorptivity allow more sulphate solution to occupy pore spaces. The reason for high mass gain in CC is because of precipitation. The GPC has exhibited relatively less gain in mass than control mix as GPC has relatively less permeability and sorptivity than CC.

Table 6

Change in Mass and Compressive strength retention of CC and GPC due to sulphate atack

\begin{tabular}{|llllll|}
\hline S. No & Immersion Period & \multicolumn{2}{l|}{ Change in Weight (\%) } & \multicolumn{2}{l|}{ Residual Compressive Strength (\%) } \\
\cline { 3 - 6 } & (months) & CC & GPC & CC & GPC \\
\hline 1 & 1 & 0.97 & 0.50 & 95.34 & 97.56 \\
\hline 2 & 3 & 1.94 & 1.47 & 93.65 & 96.13 \\
\hline 3 & 6 & 2.76 & 1.75 & 91.16 & 95.81 \\
\hline 4 & 12 & 3.95 & 2.08 & 90.14 & 93.35 \\
\hline
\end{tabular}

\subsubsection{Compressive Strength Retention}

From the test results of both GPC and CC have lost their compressive strength marginally on exposure towards sulphate solution. But when compared with CC the range of comparatively higher. Further, GPC 
has exhibited $2.7 \%, 3.34 \%, 1.97 \%$ and $1.91 \%$ of higher residual compressive strength than control concrete at the exposure period of 1, 3, 6 and 12 months respectively. Geopolymer specimens has demonstrated better performance in resisting sulphate attack because in cement concrete due to the formation of ettringite and gypsum presence of sulphate [46, 47]. Also, the formation of brucite lowers $\mathrm{pH}$ and then decomposes the $\mathrm{C}-\mathrm{S}$ - $\mathrm{H}$ leads to deterioration of concrete [42]. The test results are displayed in the Table 6 and they are depicted in the Fig. 10.

The microstructure SEM image of both GPC and CC for 12 months of exposure on sulphate solution is shown in Figs. 11 and 12. From the microstructure matrices deterioration of cement based concrete are mainly because of sulphate with $\mathrm{Ca}(\mathrm{OH})_{2}$ and calcium monosulfo aluminate leads to form gypsum and ettringite results in loss of strength retention, precipitation $[48,49]$. But in case of geopolymer specimens, it exhibits a different mechanism. The geopolymer products were not alike as the normal control concrete because of there is no hydration products exists and they are not as much of vulnerable towards the sulphate attack [44]. More number of needles like structures is visible in CC SEM image where as in GPC it was found very less and also the exposure to the magnesium sulfate solution resulted in a dense micro structure in the surface region.

\subsection{Resistance towards sulphuric acid attack 4.2.1 Visual appearance}

The physical appearance of CC and GPC are depicted in Figs. 13 and 14. The GPC specimen indicates that the shapes of the specimens are quiet intact, and also free from cracks. In contrary, some of the researchers reported in their research that GPC was suffered severe erosion on the surface when exposed to acidic medium. It must be due to $5 \%$ of sulphuric acid used to determine the acid attack [50]. Further, in case of $\mathrm{CC}$ it seems that some white precipitation exists along with some minor cracks and surface gets damaged. But the shape of the specimens is intact and dimensionally unchanged.

\subsubsection{Change in mass}

From the Table 7 and Fig. 15 it shows that loss of weight for control concrete and geopolymer concrete specimens when they are exposed to acidic medium for different immersion period. As for as cement based concrete specimens are considered, the loss of weight were taken place due to the reaction between calcium hydroxide in the concrete specimens and acid, which in turn it induce the tensile stresses results in formation of minor cracks and scrabbling of surfaces [10]. In GPC, it exhibits better performance than CC. The reason for the excellent performance of GPC are because of fineness of the source material used for dense packing and also high amount of Si and Al content and also GPC is relatively free from calcium compounds. [51]. Also, the geopolymer specimens had less weight loss under acidic environment is mainly due to the low sorptivity, water absorption and also calcium content is less. This observation is in conformity with the other researchers also [24, 52]. 
Table 7

Change in mass and compressive strength retention of CC and GPC due to acid attack

\begin{tabular}{|llllll|}
\hline S.No & Immersion Period & \multicolumn{3}{l|}{ Change in Weight (\%) } & \multicolumn{2}{l|}{ Residual Compressive Strength (\%) } \\
\cline { 3 - 6 } & (months) & CC & GPC & CC & GPC \\
\hline 1 & 1 month & 2.35 & 1.13 & 92.85 & 96.45 \\
\hline 2 & 3 month & 3.94 & 2.47 & 91.23 & 94.12 \\
\hline 3 & 6 month & 4.95 & 3.45 & 89.34 & 92.42 \\
\hline 4 & 12 month & 6.21 & 4.23 & 88.65 & 91.35 \\
\hline
\end{tabular}

\subsubsection{Compressive Strength Retention}

The strength retention of geopolymer concrete and control concrete are portrayed in the Fig. 16. From the test results, it is observed that both GPC and CC have lost their compressive strength retention marginally when they are exposed to acidic medium. The strength retention shows that GPC has demonstrated better performance than $\mathrm{CC}$ in resisting acid attack. Further, GPC has exhibited 3.6\%, 2.9\%, 3.1\% and 2.7\% higher strength attention than control mix at different exposure period. The strength retention values are depicted in the Table 7. In addition, Bakharev investigated the resistance of fly ash base geopolymer concrete against sulphuric acid and acetic acid over a period of 5 months. Test results shows, geopolymer material had excellent performance than cement concrete and the same observation had replicate in this findings also.

The SEM image of both GPC and CC specimens after 365 days of immersion in sulphuric acid solution are shown in Figs. 17 and 18. From the morphological image of control concrete it is noticed that formation of elongated crystalline structures of gypsum as it indicates the existence of high amount of gypsum. This may be the reason for high weight loss and the specimen surface become porous. In case of geopolymer specimens it may be noted that, the particles are densely packed because of the fineness of the materials used so that the GPC specimens are more resistance towards the acid attack when compared to CC [53].

\subsection{Sorptivity}

Damage of the concrete structures is occurred due to the movement of destructive substances from the contiguous areas into the concrete. Actually, various construction materials are porous in nature and they are mainly affected by means of moisture access. It is obvious that the higher porosity will adversely affect the performance of the concrete $[52,54,55]$. The various factors by which the sorptivity of concrete will get affected are mix composition, compaction, aggregate orientation and distribution etc. The existence of moisture content in the structure becomes the primary source of several durability issues. It is to be noted that low absorption properties of concrete will adhere good quality and also the quality of concrete will improve with curing age and the source and type of materials used [56]. 
The sorptivity of MK - BA GPC and Control Concrete were assessed upto 6 days ( 8640 mins) as per the guidelines prescribed. The test results of geopolymer concrete and control concrete are portrayed in the Table 8. From the table it can be noted that, the initial rate of absorption of control concrete as well as geopolymer concrete specimens are found to be 0.096 and $0.048 \mathrm{~mm} / \mathrm{t}^{1 / 2}$ respectively for the first 6 hours of duration. The final rate of absorption is 0.029 and 0.013 . From the values obtained at different time period, it is clear that both CC and GPC had exhibit reduction in sorptivity with increase in time. It is mainly because of pore refinement of matrix occurred with the age of concrete. The sorptivity value of GPC is low which means the quality of concrete endorses to be good. Further, higher compressive strength of GPC $[36,55]$ impart a low absorption of water. The low sorptivity indicates MK - BA GPC was much denser, homogeneous matrix and less permeable when compared to $\mathrm{CC}$. This has been achieved by means of filler effect of source materials micro particles which are finer and also geopolymerization reaction between source materials and alkaline activators. 
Table 8

Sorptivity of CC and GPC

\begin{tabular}{|c|c|c|c|c|c|c|c|}
\hline \multirow[t]{2}{*}{$\underset{(\min )}{\text { Time }}$ 't' } & \multirow[t]{2}{*}{$\begin{array}{l}\text { Square root of time } \\
\left(t^{1 / 2}\right)\end{array}$} & \multicolumn{2}{|c|}{ Mass (g) } & \multicolumn{2}{|c|}{ Absorption I } & \multicolumn{2}{|c|}{$\begin{array}{l}\text { Sorptivity mm/ } \\
t^{1 / 2}\end{array}$} \\
\hline & & $\mathrm{CC}$ & $\begin{array}{l}\text { MK - BA } \\
\text { GPC }\end{array}$ & $\mathrm{CC}$ & $\begin{array}{l}\text { MK - BA } \\
\text { GPC }\end{array}$ & $\mathrm{CC}$ & $\begin{array}{l}\text { MK - } \\
\text { BA GPC }\end{array}$ \\
\hline 1 & 1.00 & 0.148 & 0.069 & 0.019 & 0.01 & 0.019 & 0.010 \\
\hline 5 & 2.24 & 0.557 & 0.278 & 0.071 & 0.04 & 0.032 & 0.016 \\
\hline 10 & 3.16 & 1.273 & 0.424 & 0.163 & 0.05 & 0.052 & 0.017 \\
\hline 20 & 4.47 & 2.240 & 1.087 & 0.287 & 0.14 & 0.064 & 0.031 \\
\hline 30 & 5.48 & 3.875 & 1.935 & 0.497 & 0.25 & 0.091 & 0.045 \\
\hline 60 & 7.75 & 6.488 & 3.705 & 0.832 & 0.48 & 0.107 & 0.061 \\
\hline 120 & 10.95 & 8.973 & 4.985 & 1.150 & 0.64 & 0.105 & 0.058 \\
\hline 150 & 12.24 & 10.228 & 5.224 & 1.311 & 0.67 & 0.107 & 0.055 \\
\hline 180 & 13.42 & 11.445 & 5.722 & 1.467 & 0.73 & 0.109 & 0.055 \\
\hline 240 & 15.49 & 12.977 & 6.388 & 1.664 & 0.82 & 0.107 & 0.053 \\
\hline 300 & 17.32 & 13.566 & 6.783 & 1.739 & 0.87 & 0.100 & 0.050 \\
\hline 360 & 18.97 & 14.228 & 7.079 & 1.824 & 0.91 & 0.096 & 0.048 \\
\hline 1540 & 39.24 & 14.850 & 7.788 & 1.904 & 1.00 & 0.049 & 0.025 \\
\hline 3220 & 56.75 & 16.985 & 8.365 & 2.178 & 1.07 & 0.038 & 0.019 \\
\hline 4474 & 66.89 & 17.894 & 8.620 & 2.294 & 1.11 & 0.034 & 0.017 \\
\hline 7200 & 84.85 & 18.990 & 8.952 & 2.435 & 1.15 & 0.029 & 0.014 \\
\hline 8640 & 92.95 & 20.050 & 9.130 & 2.571 & 1.17 & 0.028 & 0.013 \\
\hline
\end{tabular}

A graph has been plotted between the absorbed water and square root of time and it is depicted in the Fig. 19. From the figure it has been observed that the absorption curves are precipitous at the initial period and at the later periods a gentle smooth curve has been noted for both CC and GPC. Further, it has been noted that at the early age the steeper curve indicates the high rate of water absorption where as the time prolongs the uptake of water due to capillary force was reduced extremely. Moreover, the rate of water absorption with respect to time was relatively less for GPC, while it is increased for CC.

\subsection{Rapid Chloride Penetration Test}


In general, one of the major forms of environmental attack on concrete is that ingression of chloride which leads to the corrosion of rebars and subsequent reduction in strength, serviceability and aesthetics of the structures. Rapid chloride penetration test has been carried out on geopolymer concrete and control concrete specimens at the age of 28 days and 90 respectively. The test results are displayed in the Table 9 and it is evident from the test results that both GPC and CC exhibited low chloride permeability into the specimens with respective to the age of curing. However, GPC has demonstrated significantly better resistance to chloride ion ingression than control concrete at all ages. The results are in conformity with the results reported by other researchers also [57, 58]. RCPT value of cement concrete presents higher value due to the presence of higher concentration of $\mathrm{OH}$-ions in pore solution. However, the $\mathrm{OH}$ ions in geopolymer concrete are completely consumed during geopolymeric reactions. Moreover, the micro filler effect of the fine particles of MK and BA inhibit the pores and develop more dense and compact micro structure, and thereby reduce the chloride ingression [59].

Table 9

RCPT of CC and GPC

\begin{tabular}{|llllll|}
\hline S.No & Mix Identity & \multicolumn{3}{l}{ Charge passed (Coulombs) } & Chloride permeability as per ASTM C 1202 \\
\cline { 3 - 5 } & $\begin{array}{l}\mathbf{2 8} \\
\text { days }\end{array}$ & $\mathbf{5 6}$ days & $\mathbf{9 0 ~ d a y s}$ & \\
\hline 1 & CC & 1687 & 1573 & 1485 & Low \\
\hline 2 & $\begin{array}{l}\text { MK - BA } \\
\text { GPC }\end{array}$ & 1282 & 1209 & 1125 & Low \\
\hline
\end{tabular}

\subsection{Water Absorption}

It is one of the important properties which influences the strength and durability of the concrete. The concrete with higher water absorption indicates the existence of porous microstructure. The higher porosity in concrete will reduce the strength and durability. From the Table 10, it is noticed that water absorption for CC and GPC were found as respectively for 7 days cured specimens. For 28 days cured specimens had reported that of water absorption for CC and GPC. From the test results, as expected GPC shows a lower percentage of water absorbed than CC. A low percentage of water absorption is a reliable reason for higher compressive strength of geopolymer concrete. From the test results it is observed that, as the day prolongs the percentage of water absorption are comparatively less because if the fineness and also the denser of the geopolymer matrix.. Also, it is very well known that in the study, water absorption was much lower, which indicates a high degree of geopolymerization [60]. Also, other researcher found that water absorption for GPC is less than $5 \%$ and the test results are in conformity with those results $[61,62]$. 
Table 10

Water absorption of CC and GPC

\begin{tabular}{|lllll|}
\hline S.No & Mix Identity & Dry Weight & Wet Weight & \% of water absorption \\
\hline 7 days & & & \\
\hline 1 & CC & 2.492 & 2.577 & 3.41 \\
\hline 2 & MK - BA GPC & 2.455 & 2.508 & 2.12 \\
\hline 28 days & & & \\
\hline 3 & CC & 2.496 & 2.554 & 2.32 \\
\hline 4 & MK - BA GPC & 2.522 & 2.551 & 1.15 \\
\hline
\end{tabular}

\section{Discussion}

The test results of the study provide a clear understand about the geopolymer specimens behavior when they are exposed to different environmental mediums. In fact, the results of the experiments conducted shows that geopolymer materials had good durability's when compared with control concrete.

1. Concrete may be susceptible to sulphate attack in the presence of moisture. Deterioration of concrete occurs when it is exposed to sulphate environment results in sulphate transport through the pore system, chemical interaction with the hydration products, stresses due to the formation of the expansive products and also precipitation of salt in pore spaces $[44,63]$. These reactions cause reduction in strength parameters and also spoil the concrete structure [46]. The GPC has demonstrated relatively higher resistance to sulphate due to absence of $\mathrm{Ca}(\mathrm{OH})_{2}$. Therefore, there is no possibility of gypsum and ettringite to form in geopolymer when it is exposed to sulphte medium $[44,64]$. Eventually, geopolymer displays relatively higher resistance to sulphate attack.

2. Usually, acid attacks leach away the calcium compounds of cement paste. MK-BA GPC accomplished good resistance against acid similar to geopolymer concrete made with geopolymer binders such as fly ash, metakaolin, bottom ash, GGBS and blended geopolymer binders [65]. It is due to less content of calcium hydroxide present in GPC. In case of geopolymer, acid attack causes predominantly depletion of sodium consequently, the ejection of tetrahedral aluminium from the alumino-silicate framework reduces the strength marginally but it is on par good when compared with $\mathrm{CC}$ [66]. In case of control concrete, sulphuric acid reacts with $\mathrm{Ca}(\mathrm{OH})_{2}$ leading to the formation of expansive gypsum. Subsequently, the gypsum reacts with $\mathrm{C}_{3} \mathrm{~A}$ and forms an ettringite However, the formation of expansive gypsum, ettringite, decalcification of C-S-H due to the attack of sulfuric acid reduce the strength and durability of control concrete significantly [15].

3. It is clear that both the GPC and control concrete exhibited reduction in sorptivity with increase in age of concrete. It is obvious that the pore refinement of the matrix takes place with the age of concrete resulting in reduction in sorptivity of concrete. However, the sorptivity of GPC is relatively less than control at all ages. The sorptivity of GPC at various ages is in perfect agreement with compressive 
strength. The compressive strength of MK-BA geopolymer concrete has continuously increased with decrease in sorptivity [55]. Further, the reduction in pore size of geopolymer concrete thereby avoiding the access of hostile liquid into the pore system [13]. Also, the higher sorptivity value of control concrete may be due to the existence of $\mathrm{CaOH} 2$. Further, the formation of calcium hydroxide during the hydration of cement which results in poor microstructure and thereby higher sorptivity value [60, 67]

4. One of the major forms of environmental attack on concrete is chloride ingression leading to corrosion of rebars and subsequently reduction in strength serviceability and aesthetics of the structure. Moreover, the poor quality of concrete and also shallow reinforcement quickly brings chlorides to some depth in the concrete and also reduces diffusion distance to reach rebar [68-69]. The rate of ingression of chloride ions depends on pore structure of concrete and in turn depends on type of binder, chemical admixture, mineral admixture, W/B ratio, gradation of aggregates, mix proportion etc [70-72]. In the present study, GPC had exhibited low chloride ion ingression as per the codal provision and also it confirms with the other researcher values also. Further, the same trend has been followed in the water absorption also.

\section{Conclusion}

In the present experimental study, the effect of metakaolin and bottom ash blended geopolymer concrete which are cured under ambient temperature was studied and their durable properties were investigated. Also, the performance of geopolymer concrete was compared with the control concrete in terms of strength retention, mass gain, chloride penetration and sorptivity. From the test results, the following conclusions were drawn:

1. The geopolymer concrete specimens had very good durability characteristics when they are exposed to sulphate medium. The solidity of the tested geopolymeric specimens depends on the type of activators used for the GPC preparation, concentration and type of cations existed in the sulphate medium. In addition to the exodus of alkalis from the geopolymer specimens into the sulphate solution, also diffusion of $\mathrm{Mg}$ and $\mathrm{Ca}$ in the specimens which has impact on strength improvement. But in case of control concrete, sulphate reacts with $\mathrm{CaOH}_{2}, \mathrm{C}-\mathrm{A}-\mathrm{S}$ and $\mathrm{C}-\mathrm{S}-\mathrm{H}$ leads to the formation of ettringite and also gypsum at later age results in strength decrement.

2. The deterioration of geopolymer materials in acidic medium is connected with depolymerization of aluminosilicate polymers and also condensation of siliceous polymers, zeolites formation which in turn direct to the loss of strength retention. In acidic environment, the deterioration of geopolymer materials is mainly because of formation of fissures in geopolymer matrix which leads to fragile grainy structures. However, the formation of expansive gypsum, ettringite and decalcification of C- S$\mathrm{H}$ due to the attack of sulphuric acid leads to reduction in strength of the control concrete.

3. Geopolymer specimens show considerably less sorptivity than the control concrete. The low sorptivity indicates that the GPC is comparatively more impervious than control concrete and also it can be control chloride ion ingression, water absorption better than the control concrete. 


\section{References}

1. Bosoaga A, Masek O, Oakey JE (2009) CO2 capture technologies for cement industry. Energy Proced $1: 133-140$

2. Zhang MH, Lastra R, Malhotra VM (1996) Rice-husk ash paste and concrete: some aspects of hydration and the microstructure of the interfacial zone between the aggregate and paste. Cem Concr Res 26(6):963-977

3. Favier A, Habert G, D'Espinose JB, De Lacailerie, Roussel N 2013, 'Mechanical properties and compositional heterogeneities of fresh geopolymer pastes' Cement and Concrete Research, vol. 48, pp. $9-16$

4. Kiattikomol K, Jaturapitakkul C, Songpiriyakij S, Chutubtim S (2001) A study of ground coarse fly ashes with different finenesses from various sources as pozzolanic materials. Cem Concr Compos 23(4-5):335-343

5. Sata V, Jaturapitukkul C, Rattanashotinunt C (2010) Compressive strength and heat evolution of concretes containing palm oil fuel ash. J Mater Civil Eng 22(10):1033-1038

6. Glukhovsky VD (1959) Soil silicates (Gruntosilikaty). BudievInik Publisher, Kiev

7. Davidovits J 1994, 'Properties of Geopolymer Cements', Alkaline Cements and Concretes, KIEV Ukraine

8. Xu H, Van Deventer JSJ (2000) 'The geopolymerisation of aluminosilicate minerals'. Int J Miner Process 59:247-266

9. Davidovits J 1999, 'Fire Proof Geopolymer cements', Geopolymer 99 Proceedings. Second International Conference, France, pp. 165-169

10. Vanchai, Sata, Apha Sathona Saowaphak \& Prinya Chindaprasirt 2012, 'Resistance of Lignite Bottom Ash Geopolymer Mortar to Sulfate and Sulfuric Acid Attack', Cement and Concrete Composites, vol. 34, pp. 700-708

11. Kornkanonk Boonserm V, Sata KP (2012) 'Improved geopolymerization of bottom ash by incorporating fly ash and using waste gypsum as additive'. \& Prinya Chindaprasirt 34:819-824 Cement and Concrete Composites

12. Ilker Bekir Topcu \& Mehmet Ugurtoprak (2011) 'Properties of Geopolymer from Circulating Fluidized Bed Combustion Coal Bottom Ash'. Material Science Engineering 528:1472-1477

13. Chaicharn Chotetanorm P, Chindaprasirt V, Sata SR, Apha Sathonsaowaphak (2013) 'High-Calcium Bottom Ash Geopolymer: Sorptivity, Pore Size and resistance to Sodium Sulfate Attack'. J Mater Civ Eng 25:105-111

14. Revathi V, Saravanakumar R, Thaarrini J (2014) 'Effect of Molar Ratio of SiO2/Na2O, Na2SiO3/NaOH Ratio and Curing Mode on the Compressive Strength of Ground Bottom Ash Geopolymer Mortar'. International Journal of Earth Sciences Engineering 7(4):1511-1516

15. Apha, Sathonsaowaphak, Prinya Chindaprasirt \& Kedsarin Pimraksa 2009, 'Workability and strength of lignite bottom ash geopolymer mortar', Journal of Hazardous Materials, vol. 168, no. 1, pp. 44-50 
16. Marin- Lopez C, Reyes Araiza JL, Manzano-Ramirez A, Rubio A, Perez- Bueno JC, Muniz- Villareal JJ, MS, Ventura- Rsmos, E \& Vorobiev, Y 2009, 'Synthesis and Characterization of a Concrete Based on Metakaolin Geopolymer', Journal of Inorganic Materials, vol. 45, no. 12, pp. 1429-1432

17. Kong LYD, Sanjayan JG 2010, 'Effect of elevated temperatures on geepolymer paste, mortar and concrete', Cement and Concrete Research, vol. 40, pp. 334-339

18. Kong LY, Daniel S, Sagoe-Crentsil JG, Kwesi 2007, 'Comparative Performance of geopolymers made with metakaolin and fly ash after exposure to elevated temperatures', Cement and Concrete Research, vol. 37, pp. 1583-1589

19. Guo W, Wu G, Jianda W, Wen Ziyun \& Yin Suhong 2008, 'Preparation and performance of geopolymers',Journal of Wuhan University of technology - materials science, vol. 23, no. 3, pp. 326330

20. De Silva P, Sagoe-Crentsil K, Sirivivatnanon V 2007, 'Kinetics of geopolymerization: Role of Al2O3 and SiO2', Cement and Concrete Research, vol. 37, pp. 512-518

21. Sagoe-Crentsil K, Luqian Weng TB \& Shenhua Song (2005) 'Effect of aluminates on the formation of geopolymers'. Material Science Engineering B 117:163-168

22. Zhang B, Kenneth JD, MacKenzie, lan WMB (2009) 'Crystalline phase formation in metakaolin geopolymers activated with $\mathrm{NaOH}$ and sodium silicate'. Journal of Material Science 44:4468-4676

23. Rovnaik P (2010) Effect of curing temperature on the development of metakaolin-based Geopolymer. Constr Build Mater 24:1176-1183

24. Moura FPacheco-Torgal, Yining Ding \& Said Jalali D (2011) 'Composition, strength and workability of alkali- activated metakaolin based mortar'. Constr Build Mater 25:3732-3745

25. Luz Granizo M, Blanco-Varela MT, Martinez-Ramirez S (2007) 'Alkali activation of metakaolins: parameters affecting mechanical, structural and microstructural properties'. Journal of Material Sciences 42:2934-2943

26. BIS 12269 - 2013 'Ordinary Portland Cement 53 grade Specification, Bureau of Indian Standards, New Delhi

27. BIS 4031 - 1988 reaffirmed (2005) Part 11 Methods of Physical Tests for Hydraulic Cement. Bureau of Indian Standards, New Delhi

28. BIS 4031 - 1999 reaffirmed (2004) Part 2 Determination of fineness by specific surface by Blaine air permeability method. Bureau of Indian Standards, New Delhi

29. BIS 4032 - 1985 reaffirmed (2005) Methods of Chemical Analysis of Hydraulic Cement. Bureau of Indian Standards, New Delhi

30. BIS 383-1970 reaffirmed (2011) 'Specification for coarse and fine aggregates from natural sources for concrete'. Bureau of Indian Standards, New Delhi

31. BIS: 2386-1963 Part 3Reaffirmed 2002, 'Indian Standard Methods of Test for Aggregates for Concrete Bureau of Indian Standards, New Delhi 
32. Logesh Kumar M, Revathi (2016) 'Metakaolin bottom ash blend geopolymer mortar - A feasibility study'. Constr Build Mater 114:1-5

33. Rangan BV (2008) 'Fly Ash Based Geopolymer Concrete', Research report GC-4, Faculty of Engineering. Curtin University of Technology, Perth, Australia, pp 1-44

34. Rangan BV (2008a) 'Mix design and production of fly ash based geopolymer concrete'. Indian Concrete Journal 82(5):7-15

35. BIS 10262 - 2009 'Concrete Mix Proportioning - Guidelines', Bureau of Indian Standards, New Delhi

36. Logesh Kumar M, Revathi (2020) 'Microstructural Properties of Alkali-Activated Metakaolin and Bottom Ash Geopolymer' Arabian. Journal of Science Enginering 45:4235-4246

37. ASTM C 1012 'Length Change of Hydraulic-Cement Mortars Exposed to a Sulfate Solution 'United States

38. ASTM C 1898-20 "Standard Test Method for determining the chemical resistance of concrete products to acid attack", West Conshohocken, PA

39. ASTM C 1585 - 13 "Standard test method for measurement of rate of absorption of water by hydraulic cement concrete", West Conshohocken, PA

40. ASTM C1202 'Standard Test Method for Electrical Indication of Concrete's Ability to Resist Chloride Ion Penetration' United States

41. ASTM C 642-13 "Standard Test Method for Density, Absorption, and Voids in Hardened Concrete", West Conshohocken, PA

42. Lee H 1999, 'Expansive mineral growth and concrete deterioration: a microstructural and micro analytical study, Ph.D. thesis, lowa State university

43. Rajamane NP, Nataraja MC, Dattatreya JK, Sabitha D (2012) 'Sulphate resistance and ecofriendliness of geopolymer concretes'. Indian Concrete Journal 86(1):13-22

44. Bakharev $T$ (2005) 'Durability of geopolymer materials in sodium and magnesium sulphate solutions'. Cem Concr Res 35:1233-1246

45. Hardjito D, Rangan BV (2005) 'Development and Properties of Low-Calcium Fly Ash-based Geopolymer Concrete'. In: Research Report GC1, Faculty of Engineering. Curtin University of Technology, Perth

46. Neville AM (2014) 'Properties of Concrete'. Prentice Hall, USA

47. Mehta PK (1983) 'Mechanism of sulfate attack on portland cement concrete- Another look'. Cem Concr Res 13(3):401-406

48. Yang S, Zhongzi X, Mingshu T (1996) The process of sulfate attack on cement mortars. Adv Cem Based Mater 4:1-5

49. Snelson DG, Kinuthia JM (2010) Resistance of mortar containing unprocessed pulverised fuel ash (PFA) to sulphate attack. Cem Concr Compos 32:523-531

50. Salma B, Urvashi K 2015, 'Durability Studies of Fly Ash based geopolymer concrete' Journal of Engineering, Research and Applications, ISSN: 2248-9622, vol. 5, no. 8, Part 4, pp. 17-32 
51. Aydin S, Yazici H, Yigiter H, Baradan B (2007) Sulfuric acid resistance of high-volume fly ash concrete. Build Environ 42:717-721

52. Suresh, Thokchom, Partha Ghosh \& Somnath Ghosh 2009, 'Acid Resistance of Fly ash based Geopolymer mortars', International Journal of Recent Trends in Engineering, vol. 1, no. 6, pp. 36-40

53. Bakharev T, Sanjayan JG, Chen Y-B (2003) Resistance of alkali-activated slag concrete to acid attack. Cem Concr Res 33:1607-1611

54. Adam AA, Molyneaux TCK, Patnaikuni I, Law DW 2010, 'Strength, Sorptivity and Carbonation of geopolymer concrete', Journal of Challenges, Opportunities and Solutions in Structural Engineering and Construction, pp. 563-568

55. Partha Sarathi Deb, Pradip Nath \& Prabir Kumar Sarker 2013, 'Properties of fly Ash and Slag Blended Geopolymer Concrete Cured at Ambient Temperature', The 7th International Structural Engineering and Constructions (ISEC - 7) Conference, At Honolulu, USA

56. Hall.C, "Water Sorptivity of Mortars and Concretes: a review", Magazine of Concrete Research, vol. 41, no. 147 , pp. $51-61,1989$

57. Kim H-S, Sang-Ho Lee \& Han-Young Moon (2007) 'Strength properties and durability aspects of high strength concrete using Korean metakaolin'. Constr Build Mater 21(6):1229-1237

58. Boddy A, Bentz E, Thomas MDA, Hooton RD 1999, 'A Multi- mechanistic Chloride Transport Model: An Overview and Sensitivity Study', Cement and Concrete Research, vol. 29, pp. 827-838

59. Prasanna Venkatesan Ramani \& Pazhani Kandukalpatti Chinnaraj (2015) 'Geopolymer concrete with ground granulated blast furnace slag and black rice husk ash'. Journal of gradevinar 67(8):41-748

60. Saravana Kumar R, Revathi V (2017) 'Some Durability Aspects of Ambient Cured Bottom Ash Geopolymer Concrete'. Archives of Civil Engineering 13(3):99-114

61. Xie T, Ozbakkaloglu T, "Influence of coal ash properties on compressive behaviour of FA- and BAbased GPC", Magazine of Concrete Research, pp. 1-14, 2015

62. Monita Olivia,Hamid R, Nikraz, "Durability of fly ash Geopolymer concrete in a Sea Water Environment", Proceedings of the concrete conference, Perth,WA, 2011

63. Ferraris CF, Stutzman PE, Snyder KA (2006) 'Sulfate Resistance of Concrete: A New Approach'. Research and Development Information PCA R\&D, Serial No, p 2486

64. Fernandez-Jimenez A, Garcia-Lodeiro A \& Palomo 2007,'Durability of alkali-activated fly ash cementitious materials', Journal of Material Sciences, vol. 42, no. 9, pp. 3055-3065

65. Palomo A, Grutzeck MW, Blanco MT 1999, 'Alkali-Activated Fly Ashes, A Cement for the Future.' Cement and Concrete Research, vol. 29, no. 8, pp. 1323-1329

66. Ali Allahverdi \& Frantisek Skvara (2005) 'Sulfuric acid attack on hardened paste of geopolymer cements part 1 . Mechanism of corrosion at relatively high concentrations'. Journal of Ceramics Silikáty 49(4):225-229

67. Esam Elawady AA. El Hefnawy RAF, Ibrahim (2014) 'Comparative Study on Strength, Permeability and Sorptivity of Concrete and their relation with Concrete Durability'. International Journal of 
Engineering Innovative Technology 4(4):132-139

68. Thomas MDA, Pantazopoulou SJ, Martin- Perez B (1995) 'Service Life Modelling of Reinforced Concrete Structures Exposed to Chlorides-A Literature Review'. prepared for the Ministry of Transportation, Ontario

69. Ahmad A, Kumar A (2013) 'Chloride ion migration/ diffusion through concrete and test methods'. International Journal of Advanced Scientific Technical Research 6(3):151-180

70. Bamforth PB 1995, 'Improving the Durability of Concrete Using Mineral Admixtures' Concrete Durability in the Arabian Gulf, pp. 1-26

71. McGrath P 1996, 'Development of Test Methods for Predicting Chloride Penetration into High Performance Concrete', Thesis PhD, Department of Civil Engineering, University of Toronto

72. Tang L, Nilsson LO 1992, 'Chloride Diffusivity in High Strength Concrete', Nordic Concrete Research, vol. 11, pp. 162-170

\section{Figures}

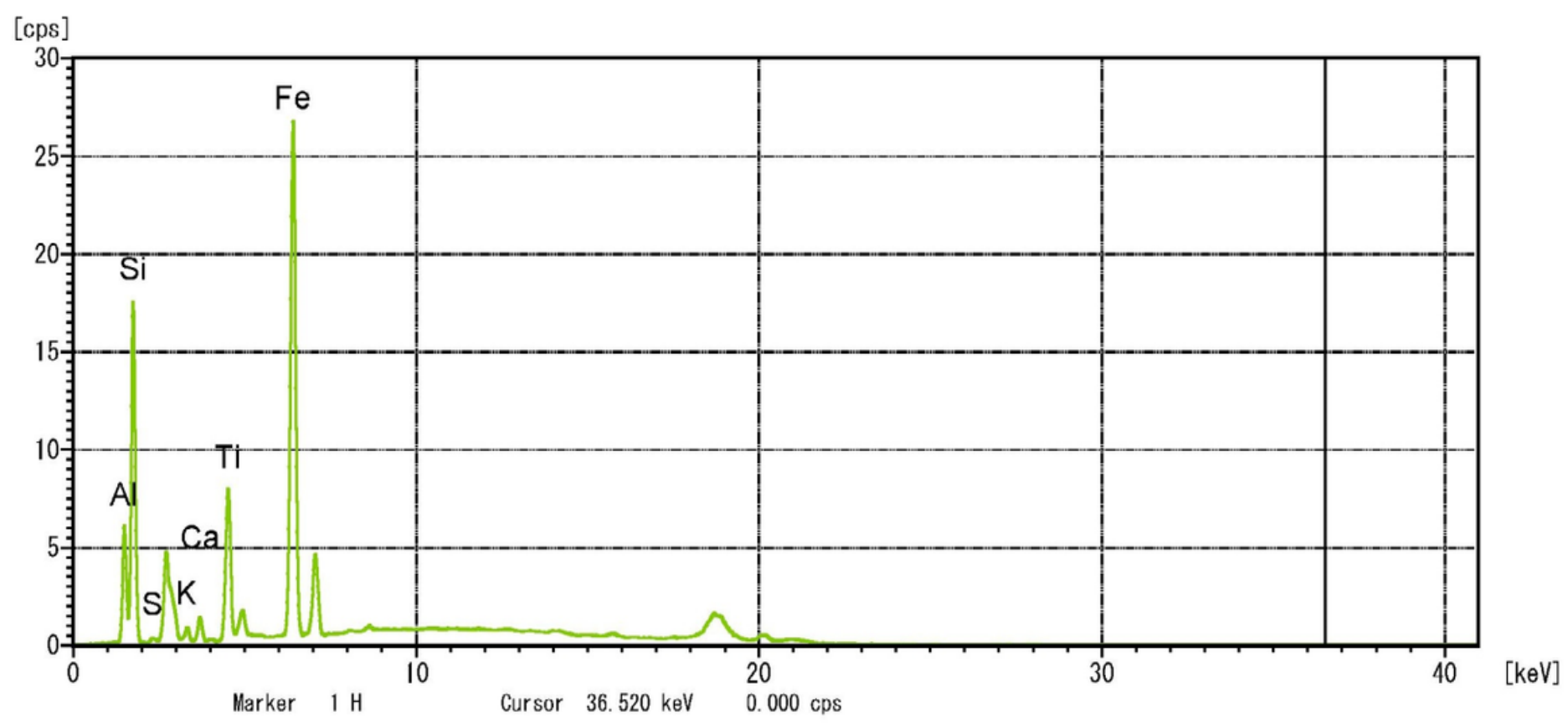

\section{Figure 1}

XRF image of Metakaolin 


\section{Glassy Structure}

\section{Impurities}

\begin{tabular}{|llll|}
\hline EHT $=15.00 \mathrm{kV}$ & Signal A $=$ VPSE G3 & Date $: 27$ Apr 2021 \\
& MD $=10.0 \mathrm{~mm}$ & Mag $=5.00 \mathrm{KX}$ & Time $: 16: 09: 49$ \\
\hline
\end{tabular}

Figure 2

SEM image of Metakaolin 


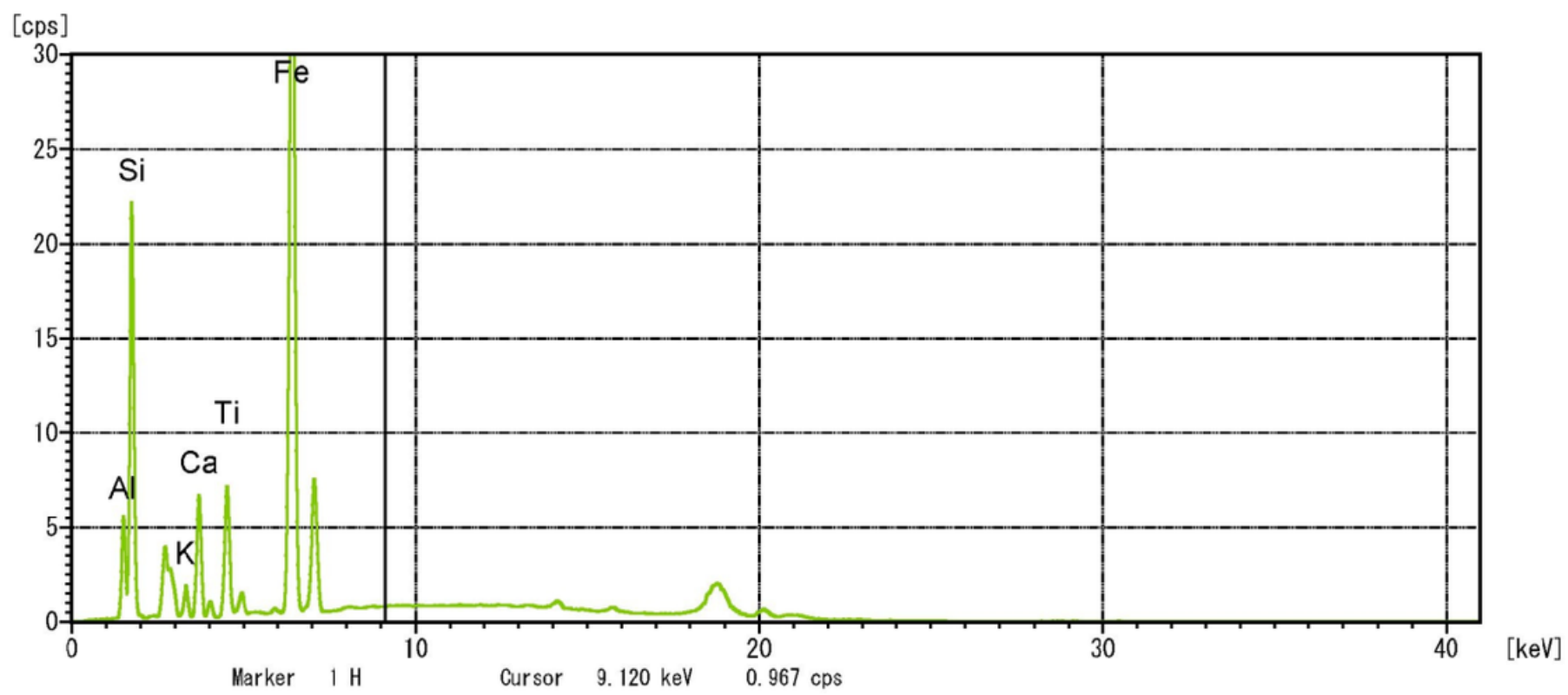

Figure 3

XRF image of Ground Bottom Ash 


\section{Spherical Ball}

\section{BrokenCenosphere}

$$
\begin{aligned}
& \mathrm{EHT}=15.00 \mathrm{kV} \\
& W D=10.0 \mathrm{~mm}
\end{aligned}
$$

Signal A = VPSE G3

Mag $=3.00 \mathrm{KX}$
Date :27 Apr 2021

Time :15:48:25

\section{Figure 4}

SEM image of Bottom Ash

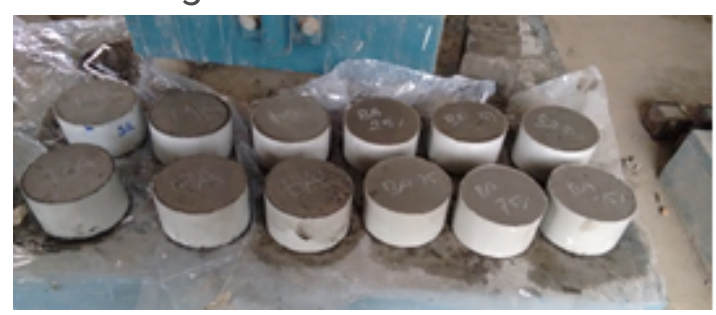

\section{Figure 5}

Specimens casted for Sorptivity test 


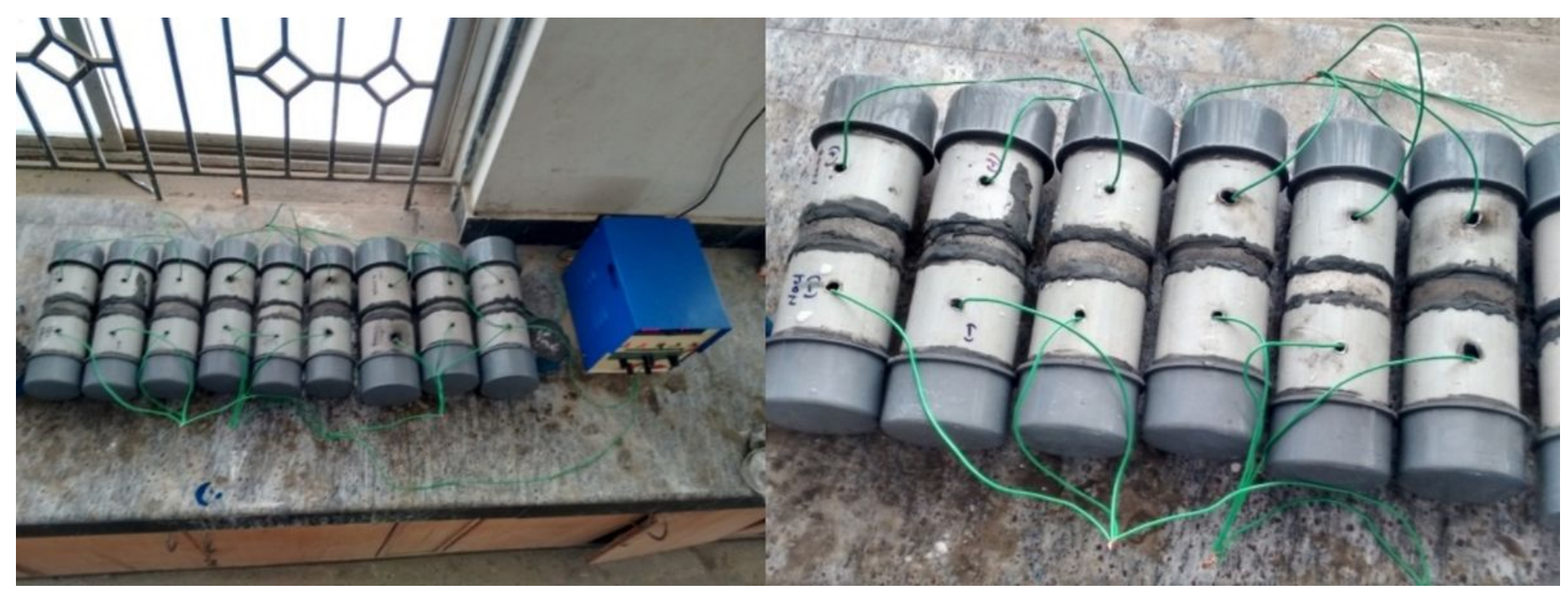

Figure 6

Specimens casted for RCPT

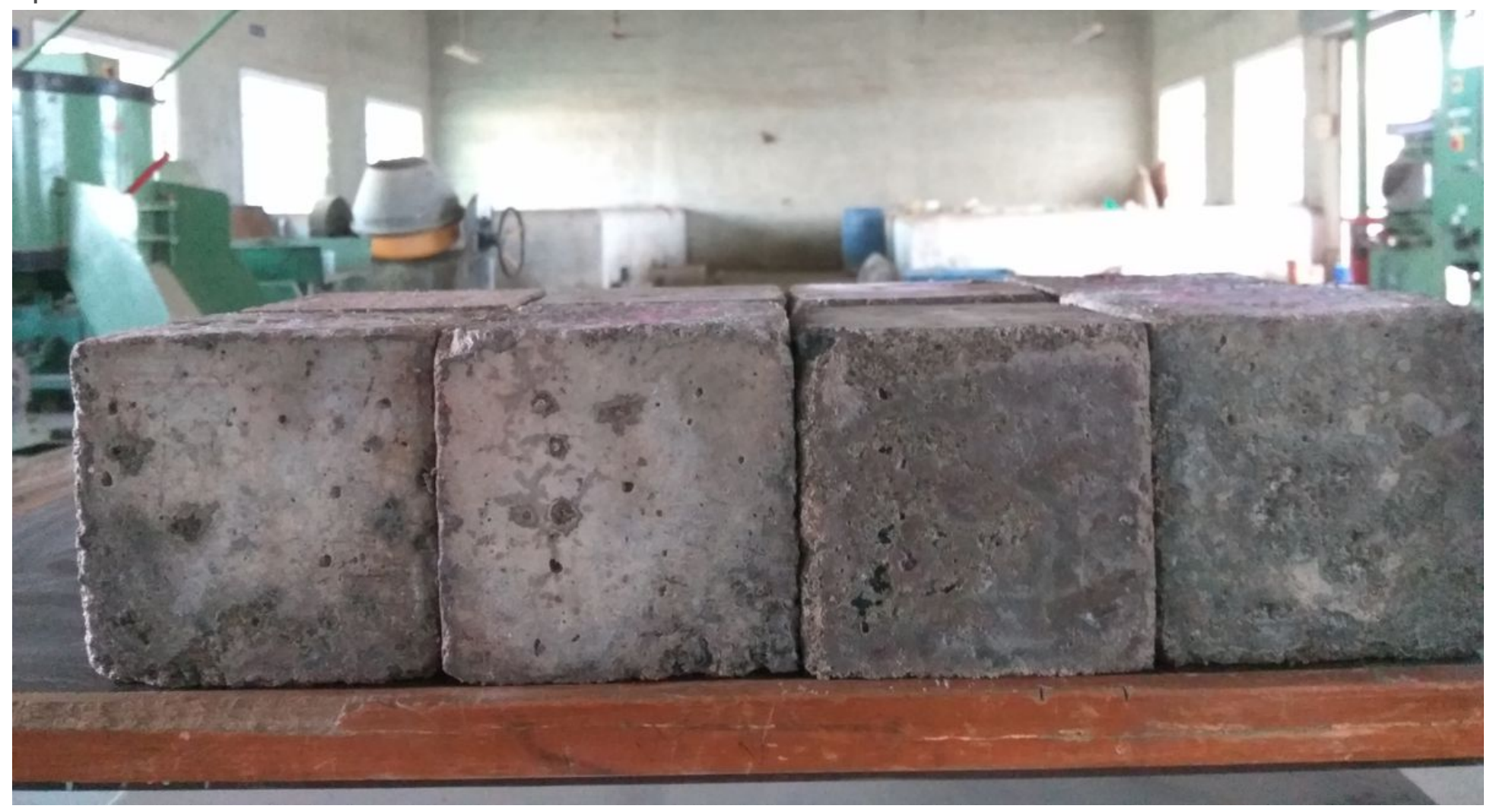

Figure 7

Visual appearances of GPC specimens after Immersion in magnesium sulphate solution 


\section{Figure 8}

Visual appearances of CC specimens after Immersion in magnesium sulphate solution

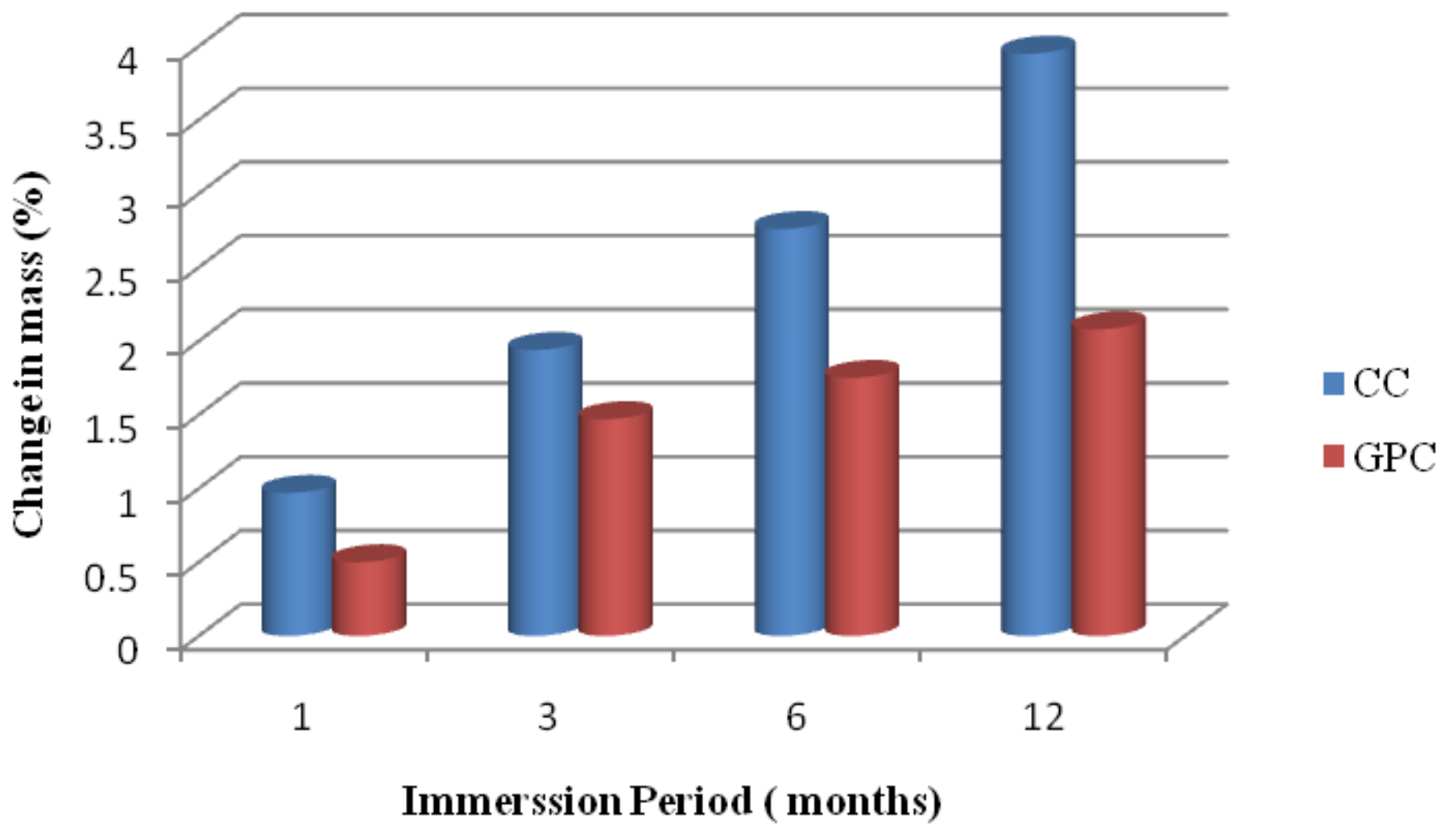

Figure 9 
Mass Gain due to sulphate attack on CC and GPC

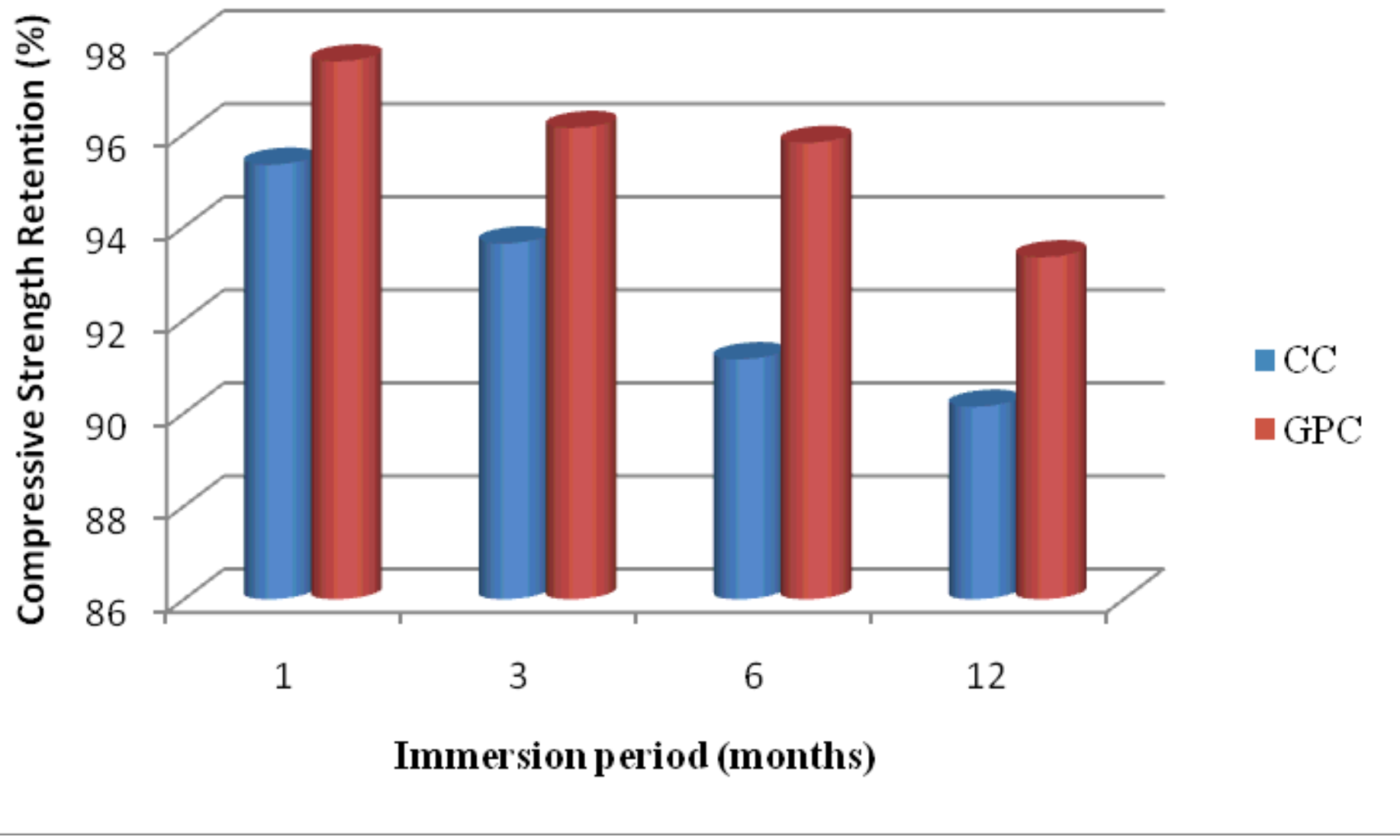

Figure 10

Compressive strength retention of CC GPC due to sulphate attack 


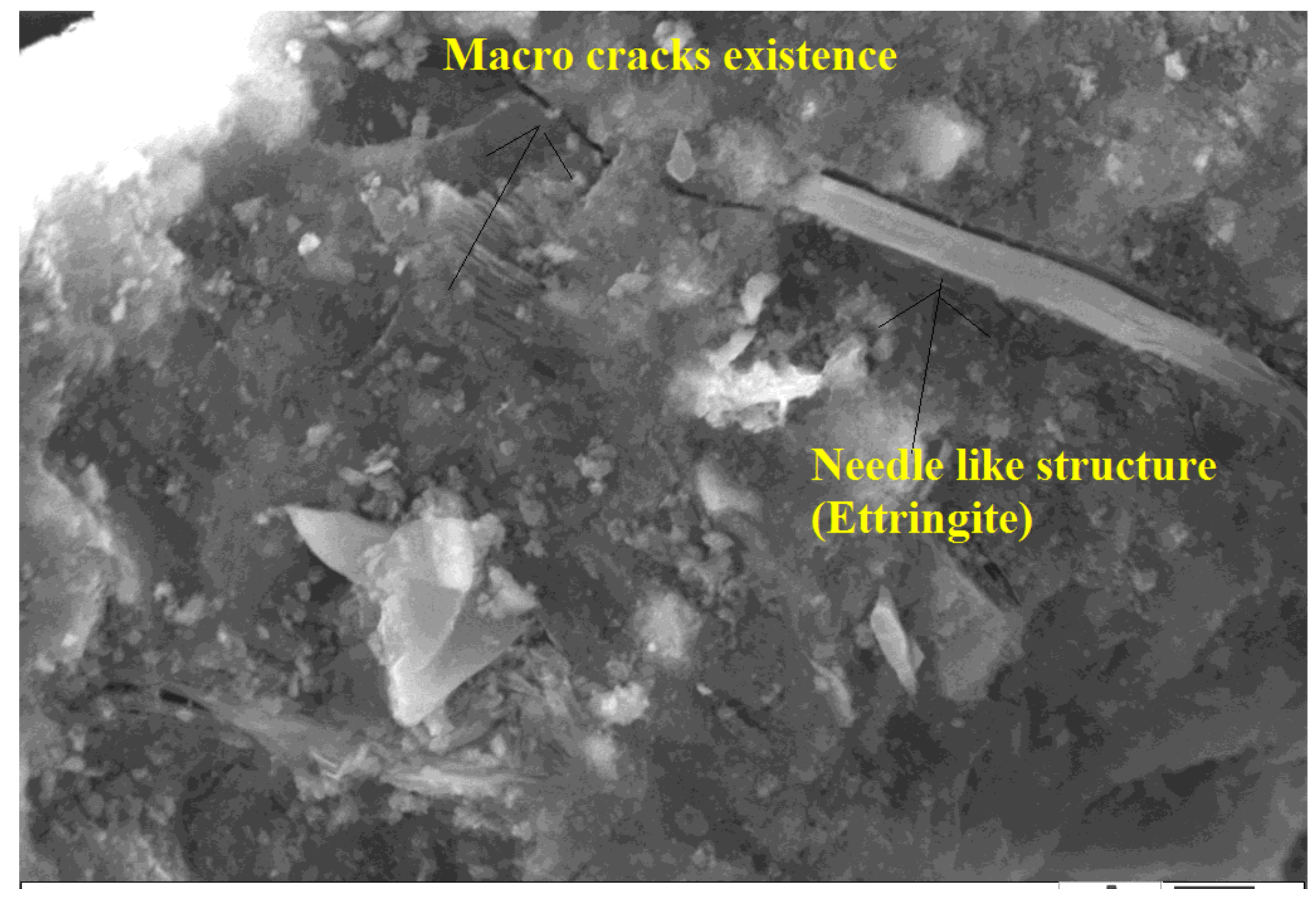

Figure 11

SEM image of CC after 12 months of immersion in sulphate solution 


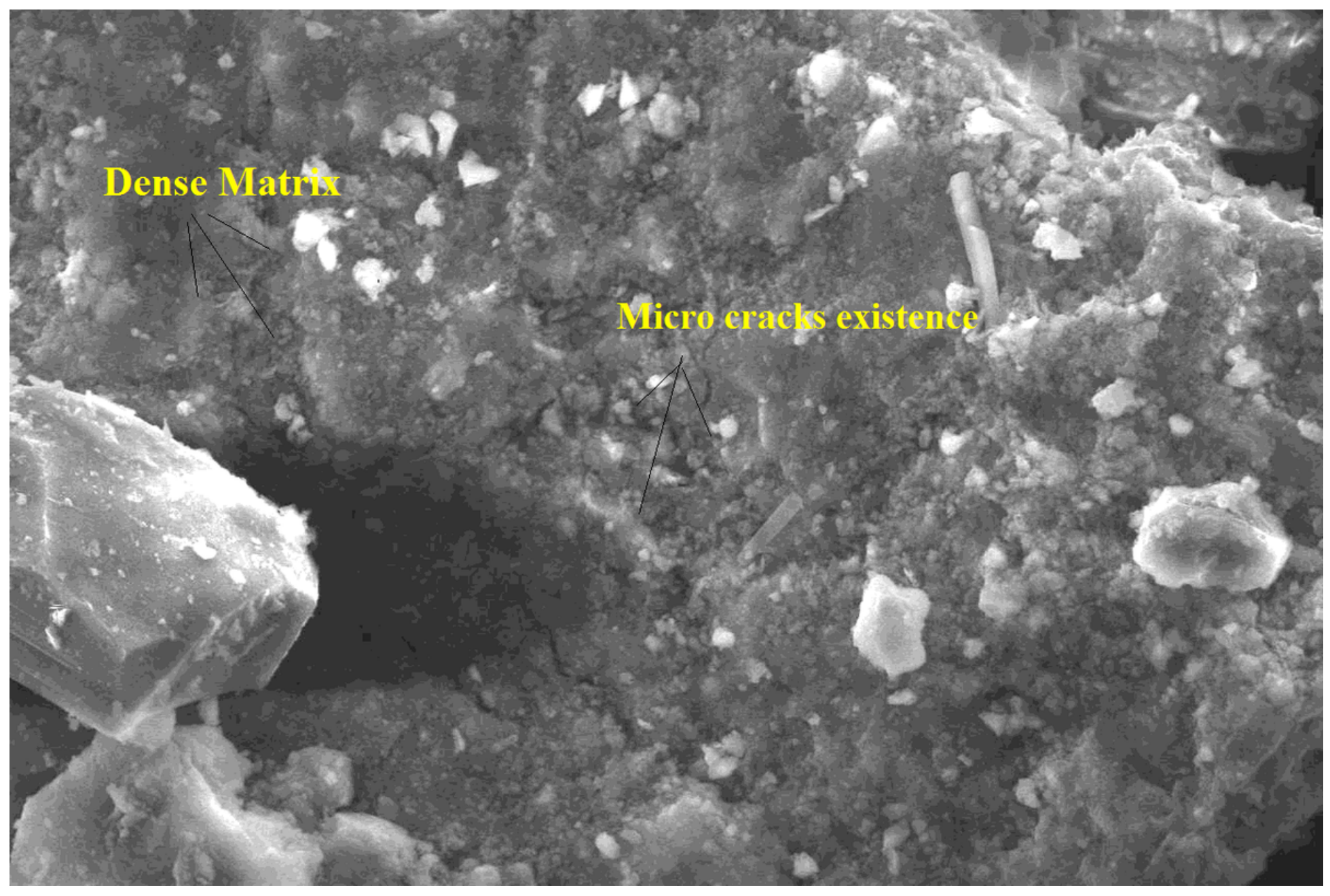

Figure 12

SEM image of GPC after 12 months of immersion in sulphate solution 


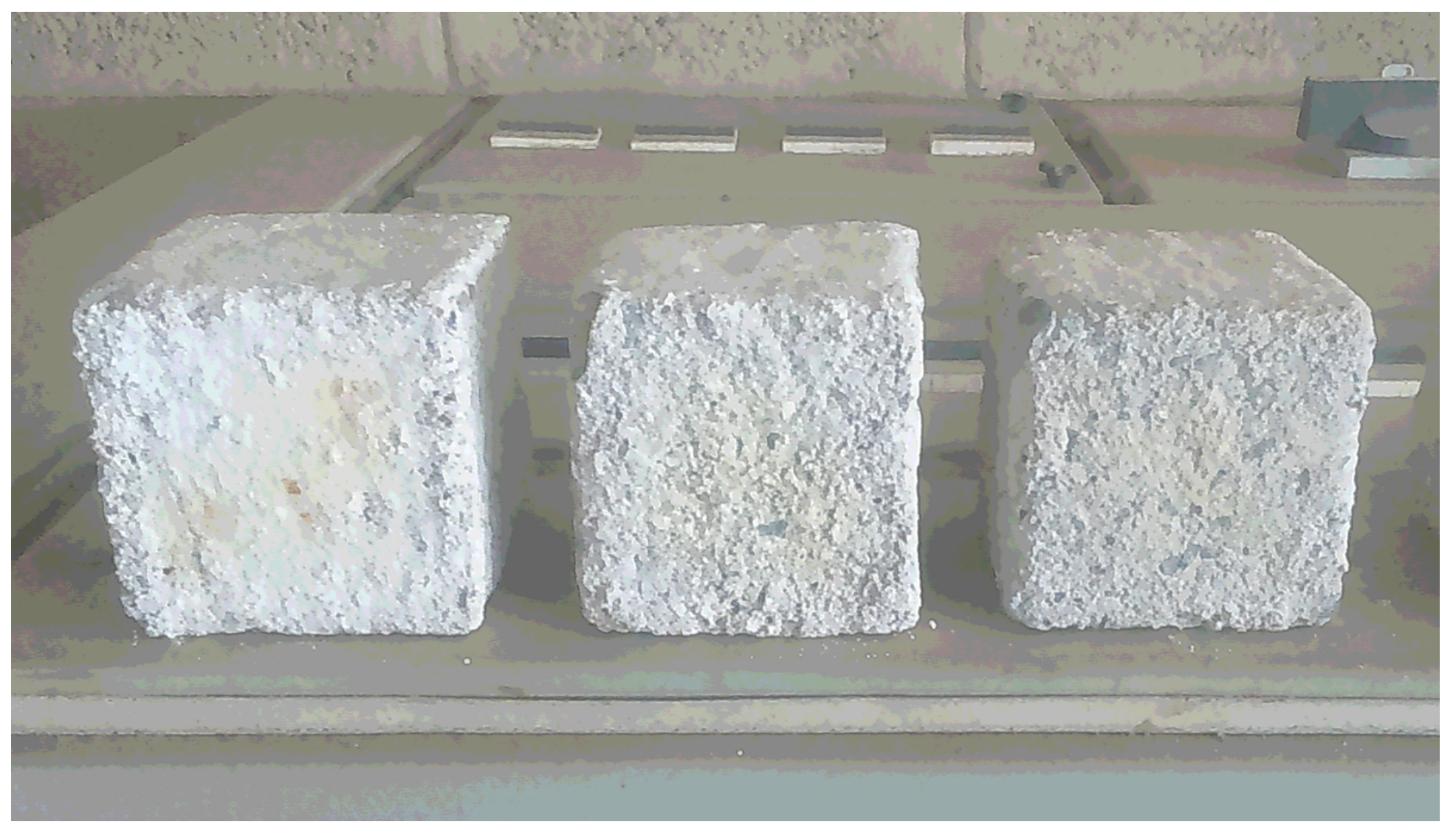

\section{Figure 13}

Visual appearance of GPC specimens after Immersion in sulphuric acid solution

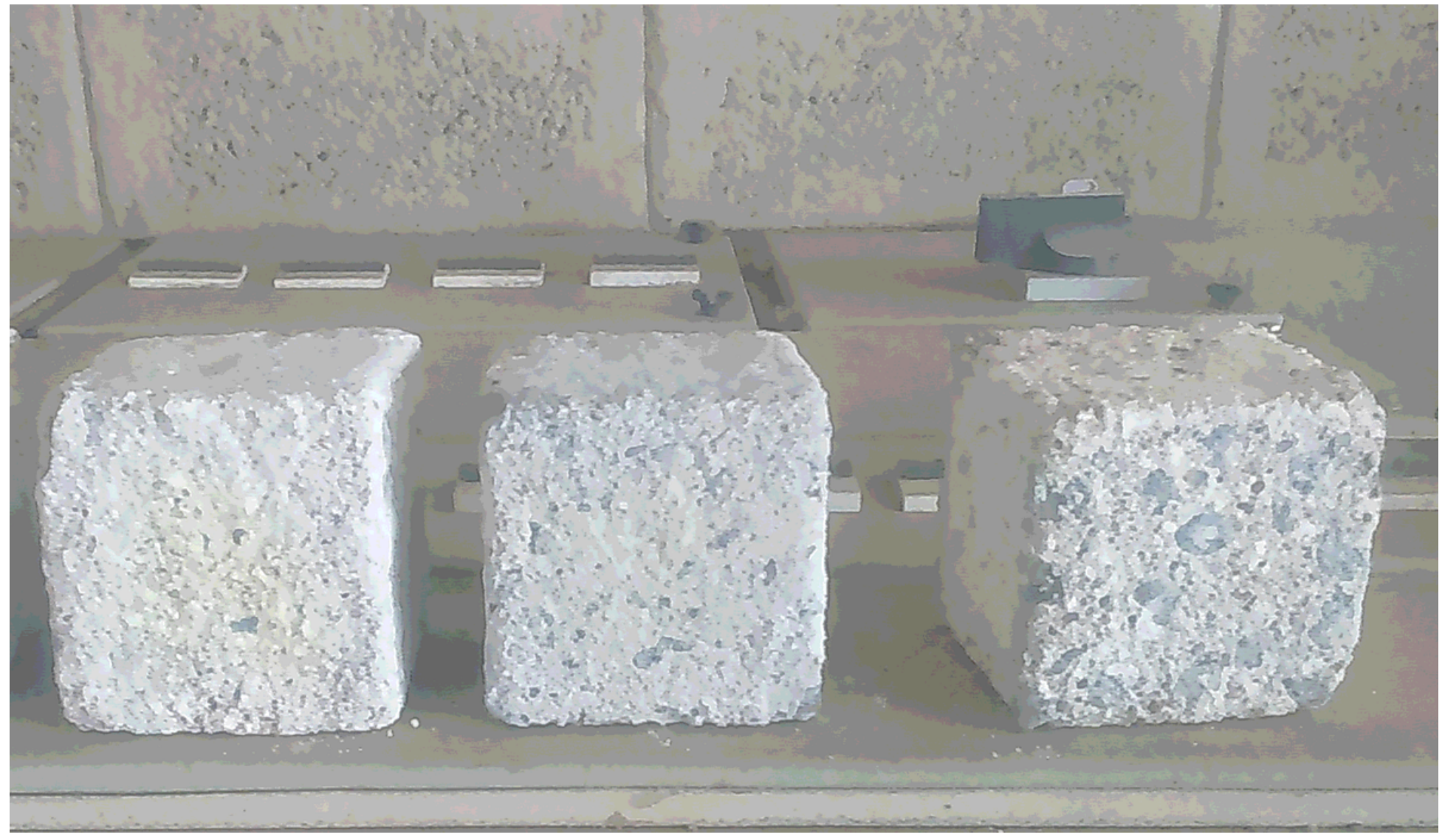


Figure 14

Visual appearance of CC specimens after Immersion in sulphuric acid solution

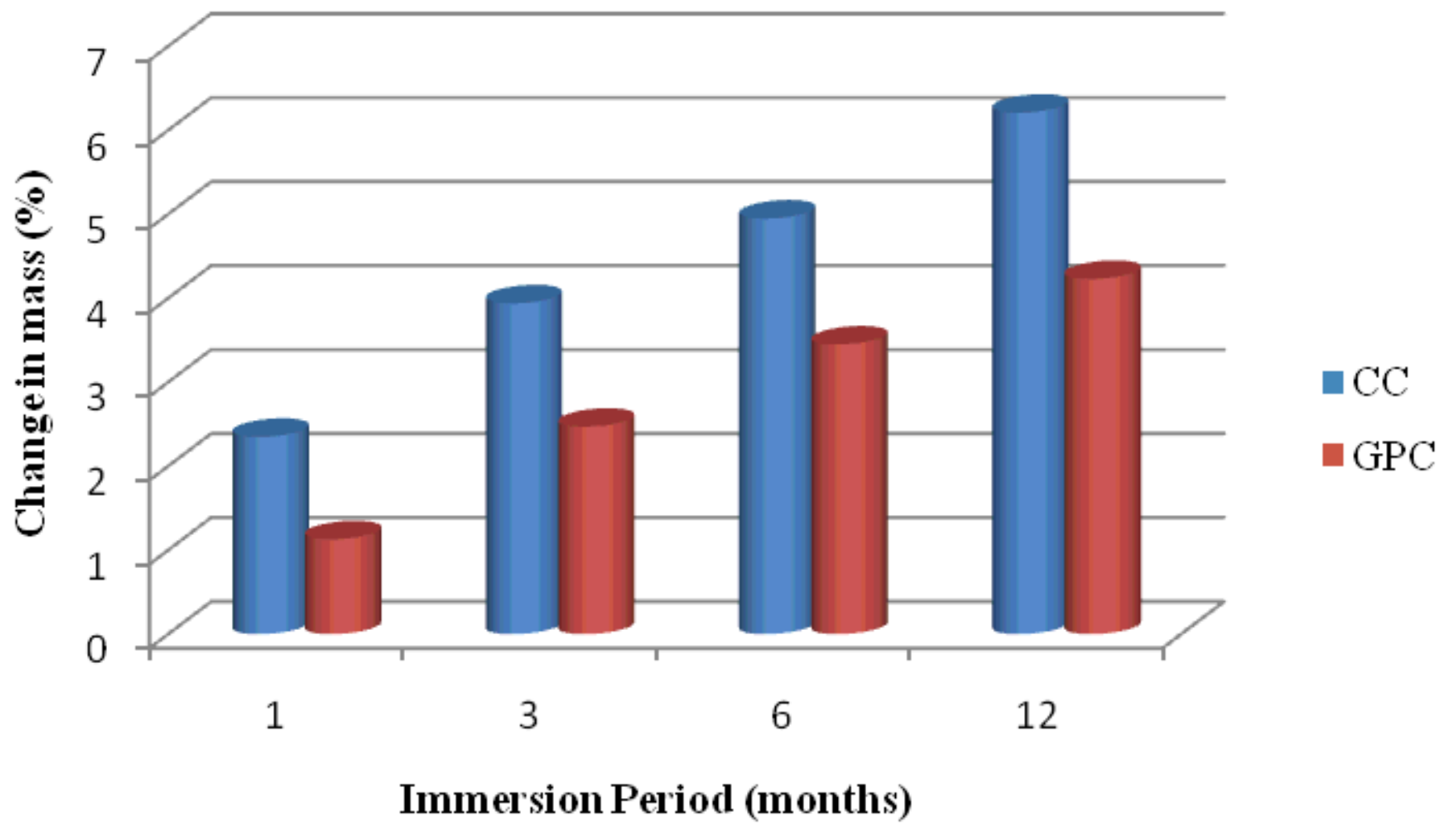

Figure 15

Change in mass of CC and GPC due to acid attack 


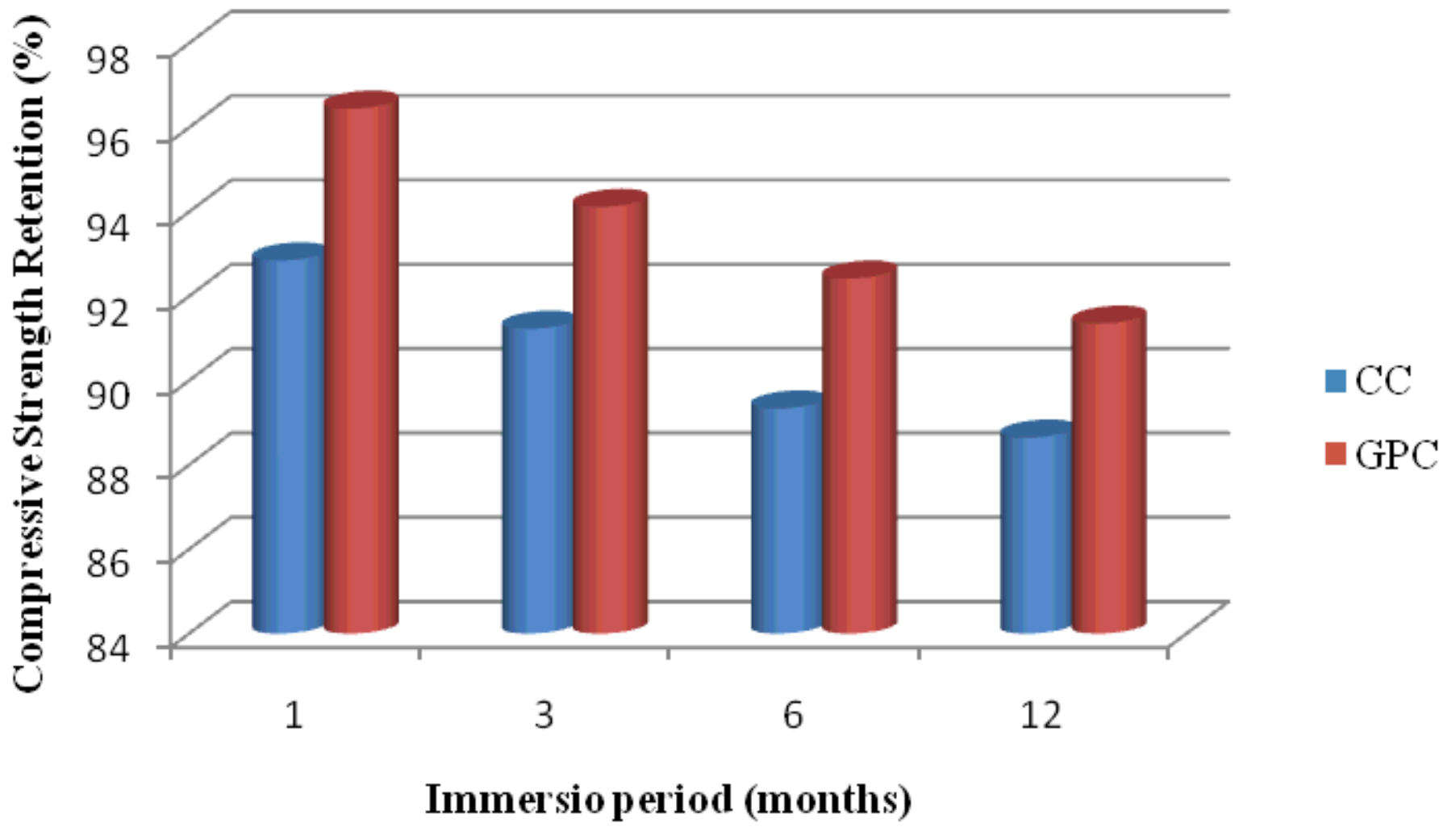

Figure 16

Compressive strength retention of CC and GPC due to acid attack 


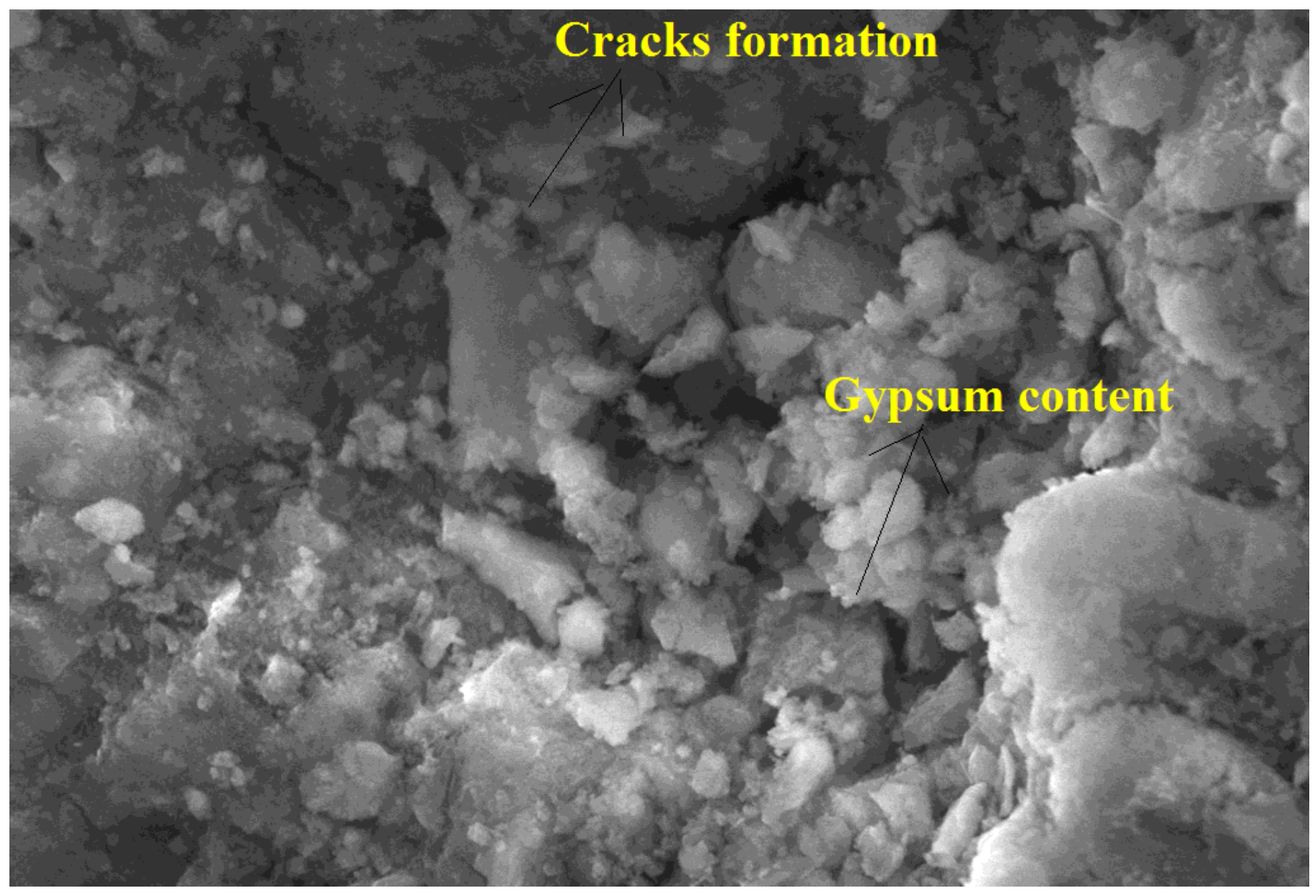

Figure 17

SEM image of CC after 12 months of immersion in acid solution 


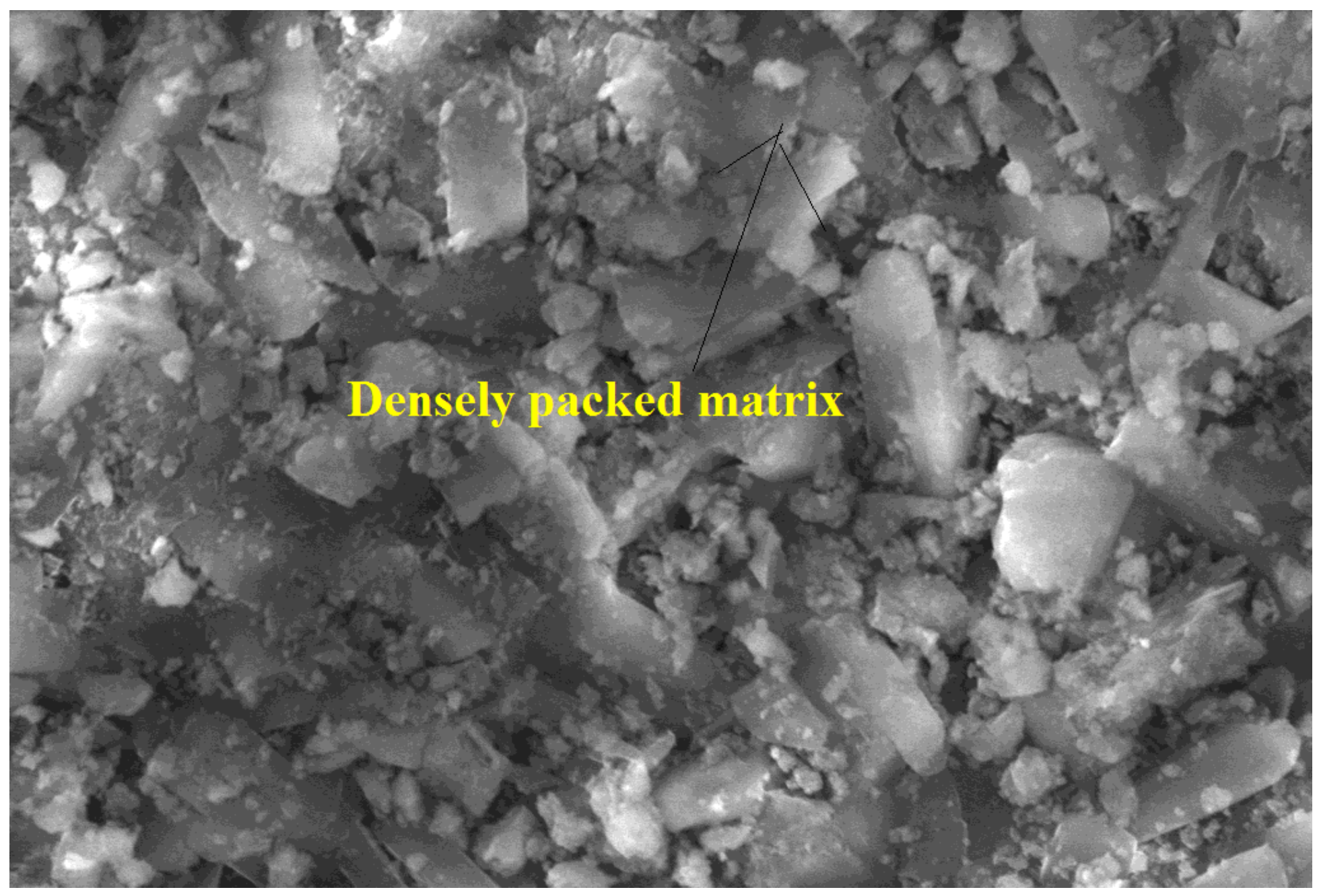

Figure 18

SEM image of GPC after 12 months of immersion in acid solution 


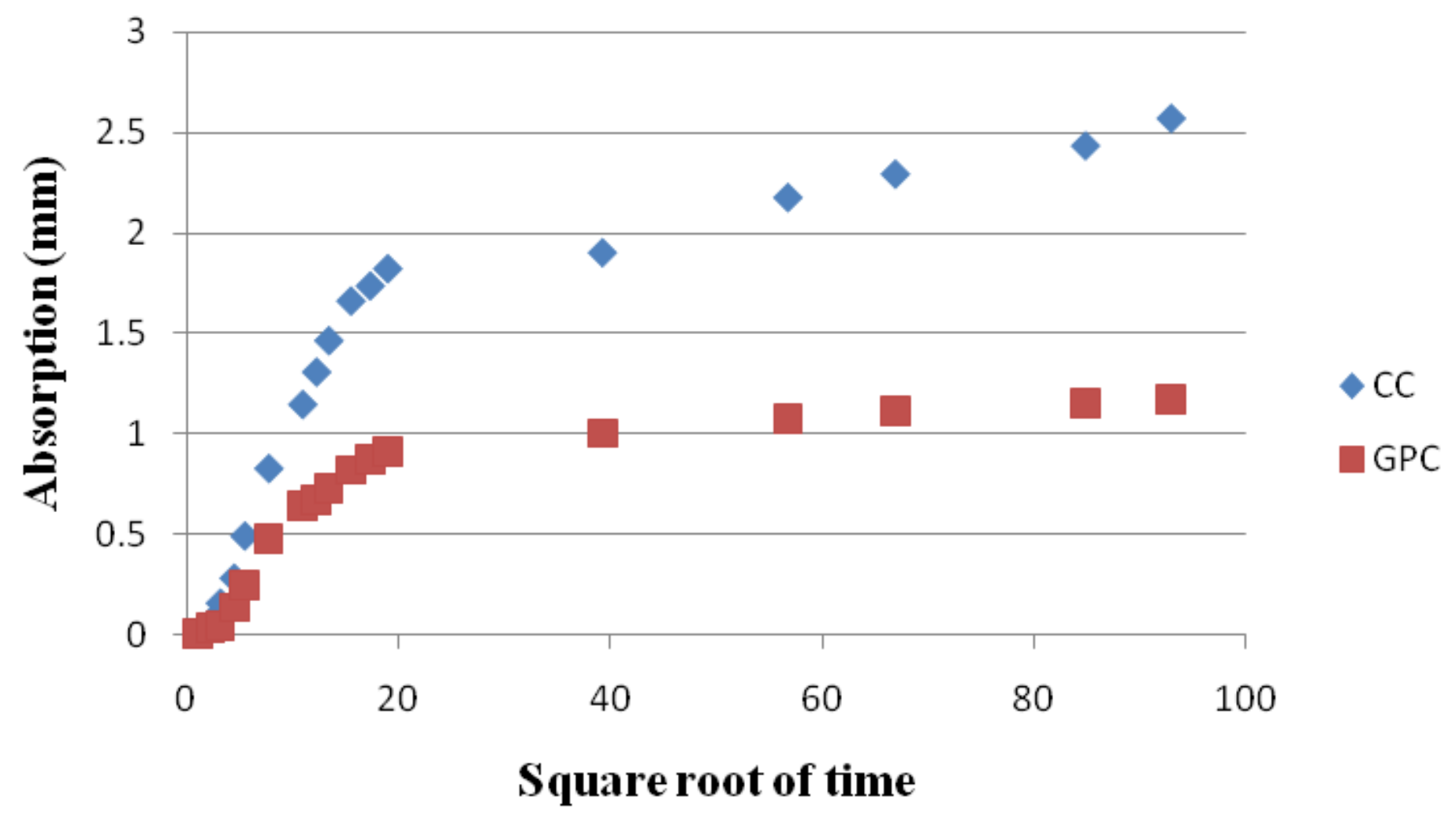

Figure 19

Sorptivity of CC and GPC 